\title{
National Action Plan
}

to Improve Health Literacy

\section{U.S. Department of Health and Human Services}

Office of Disease Prevention and Health Promotion 
Suggested citation:

U.S. Department of Health and Human Services, Office of Disease Prevention and Health Promotion. (2010). National Action Plan to Improve Health Literacy. Washington, DC: Author. 


\section{Foreword}

or more than 30 years, I've observed the difficulties many people face as they attempt to use our health care system. I've seen firsthand the inequities in health status and access to care and the outcomes that persist. My own experiences in treating patients, running a large government agency and overseeing academic research, have given me a unique perspective about the Nation's health care and public health systems, and more importantly the need to make health literacy a public health priority.

Quite simply, the responsibility is ours as health professionals to communicate in plain language. Without clear communication, we cannot expect people to adopt the healthy behaviors and recommendations that we champion. When people receive accurate, easy-to-use information about a health issue, they are better able to take action to protect and promote their health and wellness. That is why health literacy is so critical to our efforts in the U.S. Department of Health and Human Services. It is the currency for everything we do.

Improving health literacy - that is, the degree to which individuals have the capacity to obtain, process, and understand basic health information and services needed to make appropriate health decisions-is critical to achieving the objectives set forth in Healthy People 2020 and, more broadly, key to the success of our national health agenda.

We should address in a sustained manner the problem of health literacy in our Nation with a goal of improving health status within and across populations. I remain personally and professionally passionate about working systematically to attain the highest standard of health for the greatest possible number of people.

Too often, there exists a chasm of knowledge between what professionals know and what consumers and patients understand. Basic health literacy is fundamental to the success of each interaction between health care professionals and patients-every prescription, every treatment, and every recovery. Basic health literacy is fundamental to putting sound public health guidance into practice and helping people follow recommendations.

The National Action Plan to Improve Health Literacy envisions a restructuring of the ways we create and disseminate all types of health information in this country. The plan also calls us to ensure that all children graduate with health literacy skills that will help them live healthier throughout their lifespan. 
So many large and small steps are at our disposal. The time to act is at hand. This volume sets forth thoughtful, achievable objectives and describes what is required to create and sustain a health literate Nation.

Accordingly, I wholeheartedly endorse this thoughtful document and the blueprint it offers. Working cooperatively, let us realize the vision it offers in the lives of people everywhere.

Sincerely,

Howard K. Koh, M.D., M.P.H.

Assistant Secretary for Health 


\section{Contents}

Foreword. .iii

Contents ...v

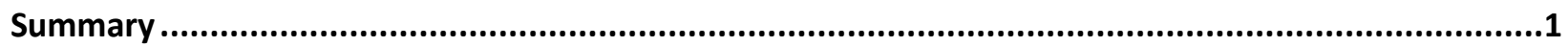

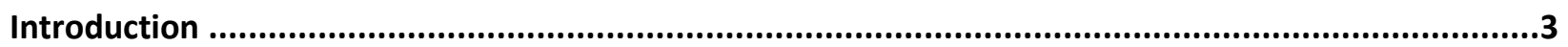

Understanding and Defining Health Literacy ........................................................................... 4

Section 1: Limited Health Literacy as a Public Health Problem ......................................................7

Prevalence of Limited Health Literacy (Epidemiology) .................................................................... 7

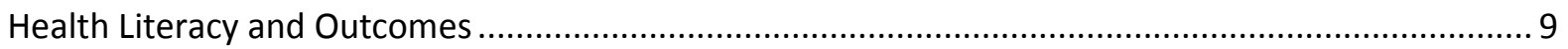

Innovative Approaches To Improve Health Literacy ...................................................................... 10

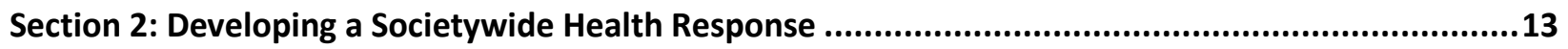

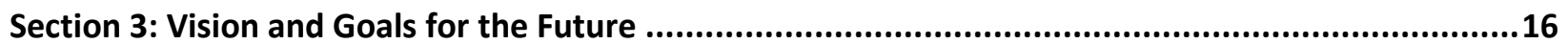

Goal 1-Develop and Disseminate Health and Safety Information That Is Accurate,

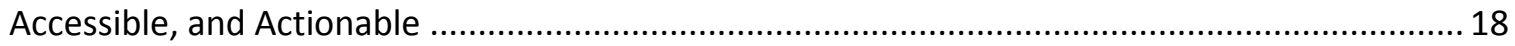

Goal 2-Promote Changes in the Health Care Delivery System That Improve Health Information, Communication, Informed Decisionmaking, and Access to Health Services ............ 25

Goal 3-Incorporate Accurate, Standards-Based, and Developmentally Appropriate Health and Science Information and Curricula in Child Care and Education Through the University Level.

Goal 4-Support and Expand Local Efforts To Provide Adult Education, English Language Instruction, and Culturally and Linguistically Appropriate Health Information Services in

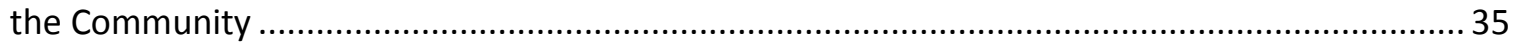

Goal 5-Build Partnerships, Develop Guidance, and Change Policies

Goal 6-Increase Basic Research and the Development, Implementation, and Evaluation of Practices and Interventions To Improve Health Literacy.

Goal 7-Increase the Dissemination and Use of Evidence-Based Health Literacy Practices and Interventions.

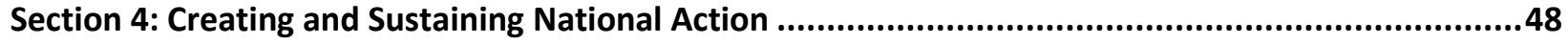

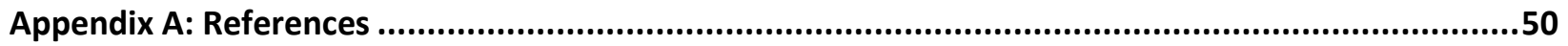

Appendix B: What You Can Do To Improve Health Literacy............................................................59

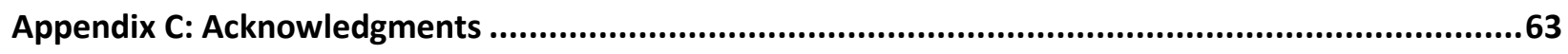




\title{
Summary
}

\begin{abstract}
his National Action Plan to Improve Health Literacy seeks to engage organizations, professionals, policymakers, communities, individuals, and families in a linked, multisector effort to improve health literacy. The plan is based on the principles that (1) everyone has the right to health
\end{abstract} information that helps them make informed decisions and (2) health services should be delivered in ways that are understandable and beneficial to health, longevity, and quality of life. The vision informing this plan is of a society that:

- Provides everyone with access to accurate and actionable health information

- Delivers person-centered health information and services

- Supports lifelong learning and skills to promote good health

Two decades of research indicate that today's health information is presented in a way that isn't usable by most Americans. Nearly 9 out of 10 adults have difficulty using the everyday health information that is routinely available in our health care facilities, retail outlets, media, and communities. ${ }^{1,2,3}$ (References are presented in Appendix A.) Without clear information and an understanding of prevention and selfmanagement of conditions, people are more likely to skip necessary medical tests. They also end up in the emergency room more often, and they have a hard time managing chronic diseases, such as diabetes or high blood pressure. ${ }^{1}$

Health literacy is the degree to which individuals have the capacity to obtain, process, and understand basic health information and services needed to make appropriate health decisions. ${ }^{4}$ Limited health literacy affects people of all ages, races, incomes, and education levels, but the impact of limited health literacy disproportionately affects lower socioeconomic and minority groups. It affects people's ability to search for and use health information, adopt healthy behaviors, and act on important public health alerts. Limited health literacy is also associated with worse health outcomes and higher costs. ${ }^{5}$

This report contains seven goals that will improve health literacy and suggests strategies for achieving them:

1. Develop and disseminate health and safety information that is accurate, accessible, and actionable

2. Promote changes in the health care system that improve health information, communication, informed decisionmaking, and access to health services 
3. Incorporate accurate, standards-based, and developmentally appropriate health and science information and curricula in child care and education through the university level

4. Support and expand local efforts to provide adult education, English language instruction, and culturally and linguistically appropriate health information services in the community

5. Build partnerships, develop guidance, and change policies

6. Increase basic research and the development, implementation, and evaluation of practices and interventions to improve health literacy

7. Increase the dissemination and use of evidence-based health literacy practices and interventions

Many of the strategies highlight actions that particular organizations or professions can take to further these goals. It will take everyone working together in a linked and coordinated manner to improve access to accurate and actionable health information and usable health services. By focusing on health literacy issues and working together, we can improve the accessibility, quality, and safety of health care; reduce costs; and improve the health and quality of life of millions of people in the United States. 


\section{Introduction}

very day, people confront situations that involve life-changing decisions about their health. These decisions are made in such places as grocery and drug stores, workplaces, playgrounds, doctors' offices, clinics and hospitals, and around the kitchen table. Only some of these decisions are made when patients and their health care providers are in a face-to-face consultation; many more are made when people are on their own and dealing with often unfamiliar and complex information. For example, they must figure out what type of health insurance they should choose; how much medicine to give a sick child, using the directions printed on a box; or how to respond to a warning about a severe public health outbreak in their area. People need information they can understand and use to make informed decisions and take actions that protect and promote their health. Yet two decades of research indicate that today's health information is presented in a way that isn't usable by the average adult. Nearly 9 out of 10 adults have difficulty using the everyday health information that is routinely available in our health care facilities, retail outlets, media, and communities. ${ }^{1,2,3}$

At the same time that health-related decisions are becoming more complex, the economic pressure of rising health care costs and the growing prevalence of chronic disease are creating a shift toward consumer-driven health care, where consumers are the primary decisionmaker of the health care they receive. Public policy is increasingly focused on the role of consumers (the public) in managing their own health in partnership with health care providers. ${ }^{1,6}$ To make appropriate health decisions and act on them, people must locate health information, evaluate the information for credibility and quality, and analyze risks and benefits. Underlying this shift toward consumer-driven care are assumptions about people's knowledge and skills that contradict what we know about health literacy in the United States.

This National Action Plan to Improve Health Literacy seeks to engage all people in a linked, multilevel effort to create a health literate society. Healthy People 2010 defines health literacy as the capacity to "obtain, process, and understand basic health information and services needed to make appropriate health decisions." 4 The goals and strategies support and will help achieve Healthy People objectives in health literacy and related areas, such as chronic diseases. Healthy People is a set of health objectives for the Nation to achieve over a decade. The objectives are informed by the best scientific knowledge and designed to measure the Nation's health over time.

The action plan identifies the overarching goals and highest priority strategies that we should pursue to create a health literate society. Health literacy is part of a person-centered care process and essential to the delivery of cost-effective, safe, and high-quality health services. ${ }^{7,8}$ The expected results of striving for 
the goals and implementing the strategies are more usable health information; more cost-effective, equitable, safer, and higher quality health services; and eventually improved health outcomes.

The action plan identifies the overarching goals and highest priority strategies that we should pursue to create a health literate society. Organizations and professional groups can use the action plan as a framework, adapt the goals and strategies to their situation, and decide on specific actions to take. Professionals, public and private sector organizations, communities, and policymakers are the intended users of the plan because they are the ones who can organize and take actions and evaluate progress toward a health literate society. Every organization and professional group involved in the development and dissemination of health information and services should have specific goals, objectives, strategies, policies, guidelines, and metrics to ensure that their actions improve health literacy. Some groups may have a bigger role than others, but we all have a contribution to make. Appendix B suggests action steps for individuals and families to take on their own or in collaboration with groups in their communities.

The health literacy action plan is the result of many years of work by numerous public and private sector organizations and individuals to draw attention to health literacy as a major public health issue. The Health Literacy Workgroup of the U.S. Department of Health and Human Services (HHS) led the preparation of the plan. The plan was based on the 2006 Surgeon General's Workshop on Improving Health Literacy, a series of town hall meetings in 2007 and 2008, and feedback from stakeholder organizations in 2009. The release of the plan is only the beginning of a coordinated process that will result in a society that is more informed, empowered, and engaged in health protection and promotion. Through interconnected, multitier, and multisector approaches, we can improve the accessibility, quality, and safety of health care; reduce costs; and improve the health and quality of life of millions of people in the United States.

\section{Understanding and Defining Health Literacy}

Health literacy is a complex phenomenon that involves skills, knowledge, and the expectations that health professionals have of the public's interest in and understanding of health information and services. Health information and services are often unfamiliar, complicated, and technical, even for people with higher levels of education. People of all ages, races, incomes, and education levels - not just people with limited reading skills or people for whom English is a second language-are affected by limited health literacy. According to research from the U.S. Department of Education, only 12 percent of English-speaking adults in the United States have proficient health literacy skills. The impact of limited health literacy disproportionately affects lower socioeconomic and minority groups. ${ }^{2}$ 
The skills of individuals are an important part of health literacy, but health literacy is not only about individuals' skills. Health literacy in the U.S. reflects what health systems and professionals do to make health information and services understandable and actionable. Professionals, the media, and public and private sector organizations often present information in ways that make it difficult to understand and act on. Publicly available health information can also be incomplete or inaccurate. Reports from HHS and the Institute of Medicine (IOM) highlight a key component of health literacy: the interaction between the skills of individuals and the requirements and assumptions of health and social systems. ${ }^{1,9}$ Consequently, the skills of health professionals, the media, and government and private sector agencies to provide health information in a manner appropriate to their audiences are as equally important as an individual's skills. ${ }^{1}$ The interactions between laypersons and professionals influence the health literacy of individuals and society.

Health literacy and literacy are closely related but not identical. Literacy is defined as a set of reading, writing, basic math, speech, and comprehension skills. Numeracy, which is part of literacy, implies a "facility with basic probability and numerical concepts." ${ }^{10}$ We need these skills to function in society every day. ${ }^{11}$ Early studies in education and adult literacy demonstrated that literacy influences a person's ability to access information, use print materials, and participate in society. ${ }^{12}$ When we apply these skills to a health context-such as reading a nutrition label, getting a flu shot, or managing a health condition-we are using health literacy skills that have developed over time. General literacy gives us some but not all the skills to understand and communicate health information and concerns. ${ }^{1}$ Years of school completed can be misleading when estimating literacy and health literacy skills. A person can have completed the required number of years of school and still have limited health literacy. In fact, approximately 45 percent of high school graduates have limited health literacy. ${ }^{2}$

Health literacy requires knowledge from many topic areas, including the body, healthy behaviors, and the workings of the health system. Health literacy is influenced by the language we speak; our ability to communicate clearly and listen carefully; and our age, socioeconomic status, cultural background, past experiences, cognitive abilities, and mental health. Each of these factors affects how we communicate, understand, and respond to health information. For example, it can be difficult for anyone, no matter the literacy skills, to remember instructions or read a medication label when feeling sick.

Health information comes from many different sources and is delivered through multiple channels-for example, discussions with friends and family; TV, radio, and newspapers; schools; libraries; Web sites and social media; doctors, dentists, nurses, physician assistants, pharmacists, and other health professionals; health educators; public health officials; nutrition and medicine labels; product pamphlets; and safety warnings. Many of these sources present different and possibly conflicting information, and some present biased or incomplete information. As a result, people confront a complex and potentially overwhelming set of health messages every day. 
To prevent or manage disease and promote health, Americans need to make sense of the health information they hear, read, and see from all of these sources. Consequently, no single group or organization can address health literacy issues on its own. Initiatives from all sectors must be linked and mutually supportive to achieve measurable improvements in health literacy across all socioeconomic levels.

All of us must work together to make sure that health information and services are provided in ways that meet the needs and interests of all people. Although many individual factors contribute to limited health literacy, eliminating barriers and improving the way health care and public health professionals, educators, and the media communicate health information offer the best opportunity to achieve a health literate society. ${ }^{1}$ 


\section{Limited Health Literacy as
a Public Health Problem}

everal recent events have drawn attention to the challenges of and possible solutions to limited health literacy. In 2000, Healthy People 2010 identified limited health literacy as a public health problem and set national objectives for its improvement. ${ }^{4}$ The oral health field produced A National Call to Action To Promote Oral Health and a research agenda for health literacy in dentistry. In 2004, IOM reported findings that health literacy is critical to improving the health of individuals and the Nation. ${ }^{1}$ At the same time, the Agency for Healthcare Research and Quality (AHRQ) published a thorough scientific review of the literature on the effect of limited literacy on a wide variety of health outcomes. ${ }^{5}$ Then, in 2006, the U.S. Department of Education released the first-ever national assessment of the health literacy of English-speaking adults in the United States, showing that limited health literacy is a widespread problem. ${ }^{2}$

Health literacy is increasingly receiving attention from major health professional organizations. The National Institutes of Health and AHRQ sponsor a program announcement to support health literacy research. Numerous health professional organizations-such as the American College of Physicians, the American Dental Association, the American Medical Association, the American Academy of Pediatrics, and the Association for Clinicians for the Underserved-have made health literacy a priority issue for their members. Accreditation organizations are developing standards for health care organizations to assess their performance in improving health literacy. Audit tools-such as the Pharmacy Health Literacy Assessment Guide (from AHRQ) and the Health Literacy Environment of Hospitals and Health Centers (from the National Center for the Study of Adult Literacy and Learning)-allow organizations to assess their own performance in addressing health literacy-related barriers. The United Nations has agreed on a goal of improving health literacy: "We stress that health literacy is an important factor in ensuring significant health outcomes and in this regard call for the development of appropriate action plans to promote health literacy." ${ }^{13}$

\section{Prevalence of Limited Health Literacy (Epidemiology)}

Recent research highlights the severity of limited health literacy. ${ }^{14}$ According to Healthy People 2010, everyday health promotion and disease prevention activities, along with effective navigation of today's health care system and response to public health alerts and recommendations, require Proficient health 
literacy. ${ }^{15}$ Adults with proficient health literacy skills can perform complex and challenging literacy activities - such as integrating, synthesizing, and analyzing multiple pieces of information in a complex document. An example of health material that requires proficient skills is a table of information about health insurance costs based on income and family size. Materials are often written at a reading level too high for most readers, ${ }^{16,17,18,19}$ and many health care professionals ${ }^{20}$ use only some of the recommended strategies when working with patients with limited health literacy.

Current population data on literacy and health literacy skills in the United States come from the 2003 National Assessment of Adult Literacy (NAAL). NAAL is commissioned by the U.S. Department of Education and measures literacy among adults. National data on adult literacy (which is related to but not the same as health literacy) document significant barriers. According to the 2003 NAAL, the percentage of adults with limited literacy skills has not improved significantly in the past 10 years. For the first time, the 2003 NAAL also studied health literacy. From the more than 19,000 adults surveyed, only 12 percent demonstrated Proficient health literacy. ${ }^{2}$ These data identify limited health literacy as a population-level problem of enormous proportion, affecting nearly 9 out of 10 English-speaking adults in the United States. There are no national data on the health literacy skills in native languages of populations in the United States with limited or no English language skills.

The most current summaries of numeracy research paint a dismal portrait. ${ }^{21,22} \mathrm{~A}$ review of research on adult numeracy concluded that research on interventions is insufficient to provide a meaningful direction for practice or additional research. ${ }^{22}$ Following its review, the U.S. Department of Education summarized, "research into instructional practices and curriculum content methodologies . . . is largely flawed, lacking in the scientific rigor necessary to make sound inferences" and found "no consistent definition of math standards." ${ }^{22}$ The U.S. Department of Education recommended a more precise understanding of reasons for dropout from developmental math and more data collection on math outcomes, learner characteristics, and relationships of characteristics and outcomes.

Although limited health literacy affects most adults at some point in their lives, there are disparities in prevalence and severity. Some groups are more likely than others to have limited health literacy. Certain populations are most likely to experience limited health literacy:

Adults over the age of 65 years

- Racial and ethnic groups other than White

- Recent refugees and immigrants

- People with less than a high school degree or GED

- People with incomes at or below the poverty level

- Non-native speakers of English 
Of great concern are the 14 percent of adults (30 million Americans) who are unable to perform even the simplest everyday literacy tasks, many of whom are not literate in English. Most of the adults with Below Basic health literacy skills would have difficulty reading a chart or simple instructions. These same adults are more likely to report that their health as poor (42 percent) and are more likely to lack health insurance (28 percent) than adults with Proficient health literacy. ${ }^{2}$ Additionally, the 54 million adults with any type of disability, difficulty, or illness are especially vulnerable and more likely to perform at the lowest literacy levels. ${ }^{23}$ Although physician awareness of the Americans with Disabilities Act has increased since its passage, adults with disabilities continue to face significant barriers to health care in facilities and communication. ${ }^{24,25}$

Based on data about students' literacy skills, limited health literacy is a significant problem for students in grades $\mathrm{K}-12$. Each day, 7,000 students drop out of school-1.2 million each year. ${ }^{26}$ The results from the National Assessment of Educational Progress (NAEP) demonstrated "that high school seniors from low-income families read on a par with middle school students from more affluent families." ${ }^{27}$ However, NAEP scores for all students do not bode well for general literacy. Only 30 percent of fourth-grade students and 29 percent of eighth-grade students scored proficient in language arts on the 2005 NAEP. ${ }^{27}$ The differences in scores between States ranged from a high of 44-percent proficient students in both fourth and eighth grades in Massachusetts to a low of only 18-percent proficient students in fourth and eighth grades in Mississippi. ${ }^{27}$

\section{Health Literacy and Outcomes}

The link between limited health literacy and poor health has been well documented. In 2004, both AHRQ and IOM published reports with comprehensive reviews of the literature on health literacy and health outcomes. Both reports concluded that limited health literacy is negatively associated with the use of preventive services (e.g., mammograms or flu shots), management of chronic conditions (e.g., diabetes, high blood pressure, asthma, and HIV/AIDS), and self-reported health. Researchers also found an association between limited health literacy and an increase in preventable hospital visits and admissions. ${ }^{1,5}$ Additional studies have linked limited health literacy to misunderstanding instructions about prescription medication, medication errors, poor comprehension of nutrition labels, and mortality. ${ }^{28,29,30,31,32,33}$

Limited health literacy has psychological costs. Adults with limited health literacy skills report feeling a sense of shame about their skill level. ${ }^{34,35}$ They may hide their struggles with reading or vocabulary. ${ }^{36}$ As a result of this and other issues, limited health literacy is often invisible to health care providers and other public health professionals. ${ }^{37,38,39}$ 
Because of the complexity of health literacy, there are no reliable and valid studies of its full impact on costs for health care services. The few published studies have focused on the costs generated by individuals identified as having "low" health literacy. For example, costs associated with medical errors may result from health literacy factors. Existing economic studies indicate that people with limited health literacy skills have higher medical costs and use an inefficient mix of services. ${ }^{40}$

One study estimates the cost of limited health literacy to the Nation's economy to be between $\$ 106$ and \$236 billion U.S. dollars (USD) annually. ${ }^{41}$ When one accounts for the future costs that result from current actions (or lack of action), the real present day cost of limited health literacy might be closer to \$1.6-3.6 trillion USD. ${ }^{41}$ In addition, substantial indirect costs are likely associated with limited health literacy, such as more chronic illness and disability, lost wages, and a poorer quality of life. Much more research is needed to make a definitive statement about the costs of limited health literacy.

Additionally, recent research has focused on health literacy as one of the critical factors in health disparities. ${ }^{42,43,44}$ The greatest opportunities for reducing health disparities are in empowering individuals and changing the health system to meet their needs. ${ }^{4}$ We cannot expect people to adopt the health behaviors and take the actions we champion without clear communication, supportive activities to build skills, and organizational changes to reduce the demands of our recommendations. ${ }^{45,46}$

\section{Innovative Approaches To Improve Health Literacy}

Evidence-based strategies to address health literacy are emerging from the fields of communication, health care, public health, and adult education. Much of the evidence on interventions comes from simplifying and improving written materials, using video or other targeted approaches to patient education, and improving patient-provider communication. Interventions have taken many forms (e.g., computer-based participatory processes, in-person Saturday school classes, and plain language and pictogram medication sheets) and have had many positive results, demonstrating that limited health literacy can be successfully addressed. ${ }^{47,48,49,50}$

\section{Adopting User-Centered Design}

Strong evidence supports involving members of the target audience in the design and testing of communication products. This participatory design process results in improved outcomes, including those for people with limited health literacy. ${ }^{51,52,53,54,55,56,57,58,59,60,61}$ Similarly, health professionals should apply proven health literacy design principles and standards to health information and services. For example, studies have shown that picture-based instructions promote better understanding of how to take medication and decrease medication errors among patients. ${ }^{50,61,62}$ Graphs may be an appealing and informative means of communicating health risk information to adults with low numeracy skills. ${ }^{63,64}$ 


\section{Using a Universal Precautions Approach}

The field of health literacy has adopted the idea of "universal precautions" from infectious disease to make the case that clear communication should be the basis for every health information exchange. ${ }^{65}$ Because it is impossible to tell by looking who may be infected with HIV or a similar disease transmitted through blood and bodily fluids, doctors, dentists, and other professionals follow a universal precautions approach. This means that they follow the same precautions, such as using gloves and other barriers, for every patient. Similarly, it is impossible to tell by looking who is affected by limited health literacy. ${ }^{66}$ For this reason, many health professionals advocate using a universal precautions approach to health communication - that is, assume that most patients will have difficulty understanding health information. ${ }^{65}$ When 9 of 10 English-speaking adults have less than proficient health literacy skills, it is an issue that affects everyone. Parker and Kreps note that even though everyone will not be at the same health literacy level, it is always best to use the clearest language possible. ${ }^{67}$

Several studies have shown that while interventions and materials that address health literacy barriers may have greater effects on individuals with limited health literacy, many of those at higher health literacy levels also prefer and benefit from them. ${ }^{61,68,69}$ By adopting universal precautions, health professionals use clear communication with everyone, regardless of their perceived health literacy skills. At the same time, providers should assess in real-time if the clear communication is working and if not, incorporate additional targeting and tailoring methods to ensure that people receive the information they need to make appropriate health decisions. ${ }^{67}$

\section{Targeting and Tailoring Communication}

Several studies have demonstrated that using targeted approaches to communication can improve selfmanagement and related health outcomes among patients with limited health literacy. Targeted approaches are adapted to meet the needs of specific groups of people, such as patients with limited literacy skills. Tailored programs and communication, on the other hand, are individually crafted based on the unique characteristics of each person. ${ }^{70,71}$ Additionally, interventions targeted for those with limited literacy skills have resulted in strong ratings for acceptability and usefulness of materials ${ }^{56}$ and for improved medication dosing and adherence. ${ }^{50}$

\section{Making Organizational Changes}

As awareness of health literacy has spread, the demand for tools to help organizations meet the communication needs of their patients has grown. Assessing an organization's strengths and weaknesses is often the first step in improving quality. Two organizational assessments have been developed to measure how well an organization is responding to the health literacy of their patients. One is a selfassessment for hospitals and health centers. This assessment includes an action plan for reducing literacy-related barriers. ${ }^{72} \mathrm{~A}$ second, designed for pharmacies, includes health literacy assessment tools 
for independent auditors, pharmacy staff, and pharmacy customers. ${ }^{73}$ Self-audit tools are being developed for health plans and primary care practices to assess their health literacy practices.

Research has also shown the need for the health care system to be more proactive and take responsibility to meet the needs of the people it serves by reducing the health literacy demands placed on individuals. Some of the changes taking place include modifying consent processes, ${ }^{74}$ redesigning forms in advance to meet low literacy needs, ${ }^{69}$ and emphasizing the importance of health literacy training for health care professionals. ${ }^{75,76}$ 


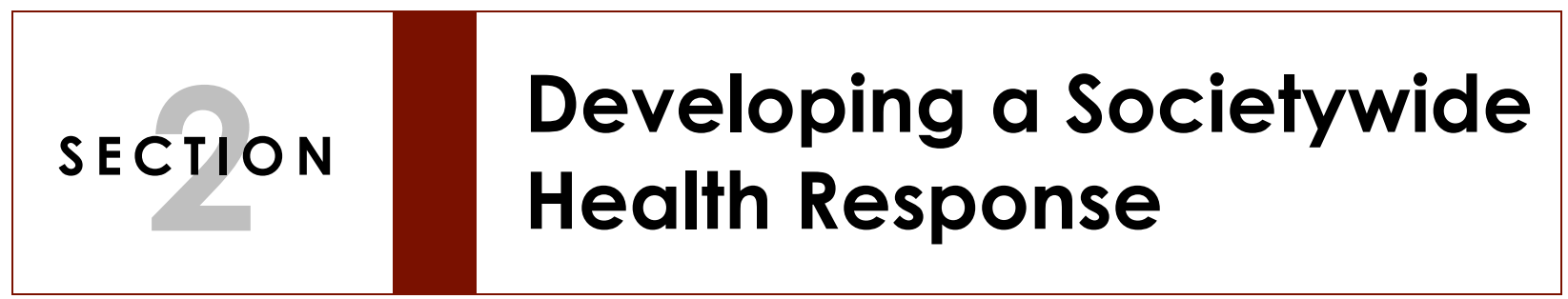

$\mathrm{T}$ o improve health literacy, we must simultaneously address the multiple factors described in the opening pages of this plan. Development of health policy, programs, and financing must address the need for increased usability of health information and services. Much can be done to improve the following:

- Communication skills of health professionals

- Framing and knowledge of complex issues by the media and public health professionals

- Clarity and accuracy of health information

- Cultural and linguistic targeting of health information and services

- Public health infrastructure that facilitates and supports healthy behaviors

- Community, educational, and workplace infrastructures that facilitate and support access to health information

Even as the number of successful evidence-based interventions increases, important questions remain: What are the most effective strategies for improving health literacy skills? How can the health care system change to better meet the information and communication needs of all people?

Determining the answers to these questions demands a multilevel public health response. In September 2006, the Office of the Surgeon General hosted a Workshop on Improving Health Literacy. The goal of the workshop was to present the state of the science in the field of health literacy from a variety of perspectives, including those of health care organizations and providers, the research community, educators, and communicators. During the 1-day workshop, participants identified the public health consequences of limited health literacy and established a framework for taking action.

The workshop led to several conclusions:

- Limited health literacy is a major public health problem in America.

- There is an association between health literacy and several health outcomes. 
- Limited health literacy is not an individual problem; it is a societywide problem that should be addressed by making sure that health information and services meet the needs of the public.

- The costs associated with improving health literacy should be weighed against the financial and human costs associated with ignoring limited health literacy.

As a followup to the Surgeon General's Workshop and in preparation for this National Action Plan to Improve Health Literacy, in 2007 and 2008, HHS convened town hall meetings across the country to explore promising practices to improve health literacy. Representatives from local organizations serving the health, education, social services, and information needs of the community were invited. To include geographically and culturally diverse perspectives, these 1-day meetings were held in New York City, Sacramento, St. Louis, and Tampa. The summaries to each townhall meeting can be accessed online at http://www.health.gov/communication/literacy/TownHall/. The morning session of each meeting focused on presentations and discussions about promising health literacy practices in the region. Each meeting had a slightly different theme. For example, the meeting in New York City focused on adult education, and the meeting in Sacramento focused on coordinated efforts by State and local governments.

During the afternoon session, participants in the town hall meetings were randomly assigned to one of four small groups and asked to develop goals for achieving a more health literate society. Imagining that it was the year 2025, participants described the characteristics of a health literate society. Based on those characteristics, each group prioritized goals and suggested strategies to achieve them.

Several themes emerged from the public meetings, including the need for cross-disciplinary and community partnerships to improve health literacy. The themes identified in the first meeting in New York City appeared at all the town halls, with varying levels of emphasis. The themes can be summarized as a STEPP approach to health literacy improvement:

- Sharing-We must share, among ourselves and across disciplinary and organizational boundaries, information, findings, program successes, and areas for improvement.

- Technology-Being mindful of the digital divide, we must consider technology as an essential tool for improving health literacy.

- Evaluation-More programs need all types of evaluation, especially evaluation that accounts for what is important to different population groups.

- Partnership-We must create partnerships with communities and each other.

- Participation-Health literacy has its roots in community engagement. We must partner with the people whom we are trying to help. 
The goals and strategies proposed in the following section build on the growing evidence base articulated in HHS' Healthy People 2010 Health Communication Action Plan ${ }^{9}$ and IOM's health literacy report. ${ }^{1}$ These goals and strategies reflect the ideas and approaches outlined in the Surgeon General's Workshop and emphasized in presentations, public dialogue, and themes during the town hall meetings. Research since the 2006 workshop has also been used to identify promising strategies. The goals and strategies also reflect the reviews and comments of many health-related organizations already working in the field of health literacy or beginning to connect health literacy to their work in other areas, such as health disparities and healthy equity. 


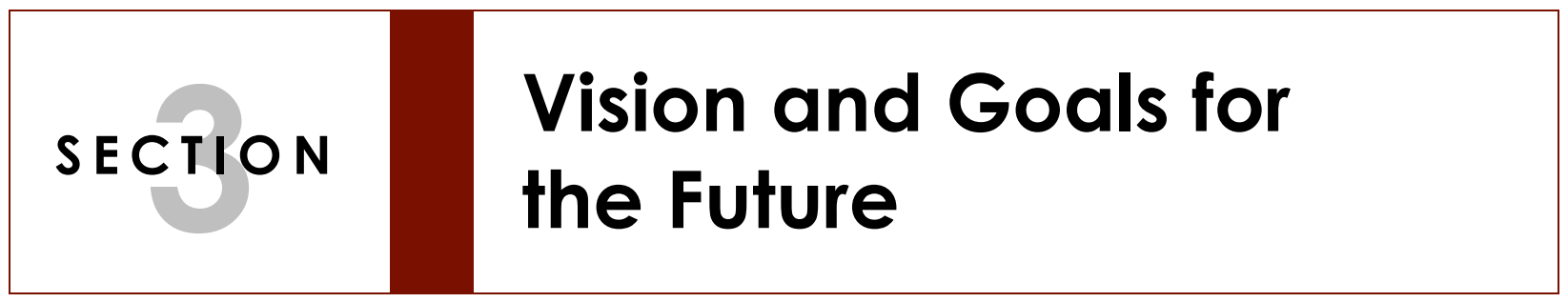

T

his National Action Plan to Improve Health Literacy is based on the principles that (1) everyone has the right to health information that helps them make informed decisions and (2) health services are delivered in ways that are understandable and beneficial to health, longevity, and quality of life. With these principles as a guide, this section suggests strategies and opportunities for action and identifies challenges that must be overcome to improve health literacy. Together, they represent a call for response from organizations and individuals that are committed to creating a health literate society.

An informed and engaged public that values health promotion, protection, and preparedness is vital to the health and security of the Nation and a significant part of the vision for a health literate future that is described in this National Action Plan. A responsive health system that eliminates barriers to clear communication and provides usable and actionable health information and services is equally important. The vision informing this plan is of a society that:

- Provides everyone with access to accurate and actionable health information

- Delivers person-centered health information and services

- Supports lifelong learning and skills to promote good health

This vision is dependent on achieving the following seven goals:

1. Develop and disseminate health and safety information that is accurate, accessible, and actionable

2. Promote changes in the health care system that improve health information, communication, informed decisionmaking, and access to health services

3. Incorporate accurate, standards-based, and developmentally appropriate health and science information and curricula in child care and education through the university level

4. Support and expand local efforts to provide adult education, English language instruction, and culturally and linguistically appropriate health information services in the community 
5. Build partnerships, develop guidance, and change policies

6. Increase basic research and the development, implementation, and evaluation of practices and interventions to improve health literacy

7. Increase the dissemination and use of evidence-based health literacy practices and interventions

These seven goals do not stand alone. Instead, they are pieces of an integrated approach to improving health literacy. We must collectively build on evidence-based programs, identify current gaps in evidence and action, and initiate and evaluate interventions to fill those gaps. This section of the National Action Plan describes the rationale that supports each of the seven goals and suggests strategies for achieving them. Many of the strategies highlight actions that particular organizations or professions can take to further these goals. It will take everyone working together to improve access to understandable and actionable health information and services. 


\section{Goal 1-Develop and Disseminate Health and Safety Information That Is Accurate, Accessible, and Actionable}

In today's communication-rich environment, people look for information about their health and safety to understand diagnoses, decide on treatments, make prevention decisions, and evaluate risks to their health. ${ }^{77}$ And we know that much of the health and safety information available is too technical, complex, and unclear about recommended actions. Safety information refers to information about avoiding injury, danger, or risk. The gap between the readability of written health information and the literacy skills of individuals is well-documented. ${ }^{12,78}$

Despite the popularity of the Internet as a news source for some age groups, many Americans get their health information from local television news. The median airtime for a health story on local television news is 33 seconds. ${ }^{79}$ One study of television health coverage documented sensational claims not supported by data, commercialism, disregard for the uncertainty of clinical trials, and single-source stories. ${ }^{80} \mathrm{~A}$ survey of journalists found that only 18 percent had specialized training in health reporting and 50 percent were not familiar with health literacy. ${ }^{81}$

The ways in which health and safety information are communicated to the public have a significant impact on health literacy. Numerous attributes of our health system contribute to poor health information:

- Technical and medical terminology in public communications

- Confusing or unnecessary statistics

- Nuanced or unclear recommendations and explanations of risk

- Over-reliance on written communication

- A focus on awareness and information rather than action and behavior

- Limited use of cultural preferences and practices when targeting and tailoring information and interventions

The average person requires access to important health and safety messages, including public health alerts and emergency preparedness instructions, in ways that make sense to them. Public health officials must provide the public and the press with clear, concrete information and advice and use communication channels and formats that aid public understanding. Public health officials must recognize that some communities face multiple communication barriers. For example, limited health literacy and limited English proficiency (LEP) frequently coexist. Therefore, interventions for vulnerable 
populations, such as those with LEP, should focus on health literacy and language to improve two-way, interactive communication. ${ }^{82}$

Key organizations and professionals play a critical role in developing and disseminating health and safety information to the public and professionals:

- Organizations and individuals that develop and disseminate health and safety information:

- Health care providers

- Public health officials

- Health communicators and educators

- Health care facilities

- Government agencies

- Commercial, academic, and nonprofit producers of health and safety information

- Payers of health care services, such as health plans, government health care purchasers, and employers

- Print, audiovisual, and electronic media

- Those responsible for food, drug, and medical device production and distribution

- Employers

Payers of health care services-including health plans, government health care purchasers, and employers-play a pivotal role because they provide to their beneficiaries general consumer health information and complex legal and medical information that pertains to rights, responsibilities, coverage, and payment of health care services. All the strategies listed for organizations that develop and disseminate health and safety information apply to health care payers.

Strategies to improve information about food, drugs, and medical devices also merit special attention. Individuals with limited health literacy skills are at particular risk for misunderstanding medical information on product labels, manuals, package inserts, and nutrition labels. ${ }^{21,22,23}$ Numerous organizations have concluded this information can be simplified to enhance understanding, adherence to intended instructions, and safe and effective use. ${ }^{83,84,85,86}$ The United States Pharmacopeia and the National Association of Boards of Pharmacy already recognize the importance of clear labeling, particularly for prescription drugs. They each have initiatives to create standards and guidelines to improve the communication of information on prescription labels. ${ }^{87,88}$ 
Because of the employment-based system of health insurance, employers play a key role in shaping available health information and services. Employers have a self-interest in having healthy employees and can be a channel for tools and resources. They can sponsor onsite programs that build employees' health literacy skills and can help insurance companies and health information providers create employeefriendly information and services.

\section{Strategies for Organizations and Individuals That Develop and Disseminate Health and Safety Information}

- Participate in ongoing training in health literacy that focuses on improving clear communication and information design practices

- Involve members of the target population-including persons with limited health literacy-in planning, developing, implementing, disseminating, and evaluating health and safety information

- Ensure that health and safety information is culturally and linguistically appropriate and motivating

- Issue plain language guidance for the development of all public health and safety information

- Include specific steps for taking action and aligning information with services and supports available in the community

- Build networks with community and faith-based organizations, social service agencies, and nontraditional partners - such as foster care services, poison control centers, and literacy service providers - to deliver health and safety information to different points in the community

- Leverage technology and electronic health tools to deliver health information and services at the time, in the place, and in the multiple formats people need and want

- Ensure access to the Internet and devices that deliver health information services

- Promote health literacy improvement efforts through professional and advocacy organizations

- Create documents that demonstrate best practices in clear communication and information design

- Test consumer health information and Web sites to ensure that consumers understand the information and can take appropriate actions 


\section{Strategies for Payers of Health Care Services}

- Review and analyze existing laws, policies, and regulations that make all types of health information (e.g., general health, safety, medication, health care coverage, financing, and informed consent) difficult to use

- Ensure that all consumer health communication-including applications, benefits materials, rights and responsibilities, letters, and health and wellness information-incorporate health literacy principles

- Develop campaigns that bring awareness to health literacy issues in health care organizations

- Build partnerships with physicians as part of a multidisciplinary team that works to improve the health literacy skills of the care team and consumers

- Develop metrics to assess organizational results from health literacy improvement efforts

\section{Strategies in Action}

\section{Creating Understandable Health Information Improves Access to Care}

The California Medical Assistance Program (Medi-Cal) recently partnered with the University of California-Berkeley School of Public Health to help seniors and people with disabilities understand their Medi-Cal health care choices. The School of Public Health used participatory design to create a guidebook in English, Spanish, and Chinese that explains enrollment options and benefits. The guidebook is easy to understand and includes accurate cultural adaptations. An evaluation showed that the guidebook has increased understanding of enrollment options and the capacity to make choices.

For more on this strategy, visit the townhall summary at http://www.health.gov/communication/literacy/TownHall/ca.htm

\section{Strategies for Print, Audiovisual, and Electronic Media}

- Include training on health reporting and health literacy in schools of journalism and public health

- Report consistent, clear messages with action steps for health promotion and disease prevention

- Use local, community, and ethnic media to raise awareness of health information and services in the community and overcome barriers to care 
- Tell stories about the impact of poor-quality health information and services on people and organizations in the community

- Work with entertainment producers and writers to increase the amount of accurate health information in all mass media programming

- Support and participate in media literacy and information literacy projects

- Engage professional associations (e.g., the Association of Healthcare Journalists) and social media users (e.g., bloggers) in raising awareness of and action on health literacy issues

- Use emerging technologies to reach all segments of society with accurate and actionable health information

\section{Strategies in Action}

\section{Using Radio To Improve Health Literacy}

Radio Bilingue is the only Latino radio network in the United States, reaching out to listeners in nearly 80 communities across the country. The network features La Cultura Cura, a radio campaign that promotes health and wellness for Spanish-, Mixtec-, and Triqui-speaking farm workers and their families. Language and cultural barriers often keep this population from accessing health care and navigating the medical system.

La Cultura Cura includes talk shows, feature news reports, educational messages, and mini radio dramas-all designed to create health behavior changes, community action, and public policy changes. An evaluation of a recent campaign found that 66 percent of listeners have discussed health programming with others. ${ }^{89}$ Moreover, the new reports have prompted new pesticide drift regulations and prompted regulations that address health-related illness and death in fields in California.

For more on this strategy, visit the townhall summary at http://www.health.gov/communication/literacy/TownHall/ca.htm

\section{Strategies for Those Responsible for Food, Drug, and Medical Device Production and Distribution}

- Standardize prescription drug labels and ensure that consumers understand such information

- Standardize consumer-directed information about and ensure consumers' understanding of prescription drugs 
- Encourage industry and academia to develop and test innovative ways to improve over-thecounter (OTC) drug labels that will help to ensure safe and effective use

- Ensure that instructions and risk and benefit information about medical devices for use by consumers are written in plain language and consumer-tested for usability

- Increase the quantity and quality of consumer health information and decision-aids about foods and healthy eating where people shop and eat

- Ensure that advertisements about medical devices, food, and prescription and OTC drugs are consistent with current public health and medical recommendations

\section{Strategies in Action}

\section{Collaborating With Target Populations To Create Culturally Relevant Materials}

Researchers at the H. Lee Moffitt Cancer Center in Tampa, Florida, set out to adapt an English language stress management toolkit for Latinas undergoing chemotherapy. Staff at the Center worked with the community to identify information needs, communication preferences, and stress triggers. The toolkit was field tested and revised to incorporate Latina preferences, which revealed a strong interest in learning cause and effect as it relates to health issues. The testing results demonstrate the importance of going beyond translations to adaptation and transcreation, an approach that involves creating linguistically and culturally adapted materials for different ethnicities and cultures. To date, the project has resulted in meaningful collaborations with community members and has refined a model for creating health interventions that are culturally relevant and meet the literacy skills of the population.

For more on this strategy, visit the townhall summary at http://www.health.gov/communication/literacy/TownHall/fl.htm

\section{Strategies for Employers}

- Develop workplace policies that increase and improve health information and services for employees and their families

- Ensure that information and services are culturally and linguistically appropriate

- Engage employees in evaluating health and wellness information

When selecting existing health and insurance information products, choose products that have been developed using health literacy principles and are culturally and linguistically appropriate 
- Consult local librarians to help build an appropriate collection of health and insurance information products and to connect with community resources

- Negotiate with health insurers to provide employee-tested health information and ensure that the information is culturally and linguistically appropriate

Provide training, tools, and resources for employees to improve their health information-seeking and decisionmaking skills

\section{Strategies in Action}

\section{Teaching Health and Literacy}

The Florida Literacy Coalition, Inc., created a health literacy class for Latinas and their children that incorporates cultural practices, values, and family. An evaluation of participants showed increased understanding of health tasks, such as completing a basic medical form and understanding how to make an emergency phone call. ${ }^{90}$

For more on this strategy, visit the townhall summary at http://www.health.gov/communication/literacy/TownHall/fl.htm 


\section{Goal 2-Promote Changes in the Health Care Delivery System That Improve Health Information, Communication, Informed Decisionmaking, and Access to Health Services}

Our Nation's health care system is inherently complex. It includes clinical and public health services. Many Americans are forced to piece together health care coverage and financing to receive health care. Health insurance information for enrollment, use of benefits, coverage, and out-of-pocket costs is complicated and often unfamiliar for even highly literate individuals. Recent shifts in the delivery of care-including specialization and fragmentation of care, an emphasis on self-management, and complex financing and coverage requirements-have placed additional demands on patients to be informed and proactive about their health.

Many factors in the current health care system contribute to limited health literacy, including:

- Lack of coordination among health care providers

- Confusing forms and instructions

- Limited use of multimedia to convey information

- Insufficient time and incentives for patient education

- Differences in language and cultural preferences and expectations between doctors and patients

- Overuse of medical and technical terms to explain vital information

The quality of clinician-patient communication can affect health outcomes, including how well patients follow instructions from clinicians. ${ }^{43,82,91,92}$ But few health care professionals receive much formal training in communication, particularly in working with people with limited literacy ${ }^{93,94}$ In recent years, the National Board of Medical Examiners has added a 1-day clinical skills exam for all medical students that includes an assessment of communication and interpersonal skills. Currently, the clinical skills test does not address how limited health literacy affects interactions with patients. Because health literacy is a relatively new clinical concept, most health care professionals already in practice have not had formal training in improving communication skills; although a growing number of continuing medical education courses in health literacy are available. The American Medical Association, the HHS Health Resources and Services Administration, the Centers for Disease Control and Prevention (CDC), and the Medical Library Association, for example, have low or no-cost training available for professionals who provide health services. 
In addition, more must be done to meet the needs of people whose primary language is not English or who have a disability that affects their communication skills. Forty-seven million people in the United States over age 5 speak a language other than English at home, and 21 million adults have LEP. ${ }^{95}$ Although Title VI of the Civil Rights Act of 1964 protects the rights to medical care for people with LEP, language barriers-particularly in the availability of medical interpreter services-continue to exist. ${ }^{96}$ Individuals with communication disorders - such as impaired hearing or eyesight, aphasia, or autismface special health literacy challenges. Communication barriers for persons with disabilities have been documented. ${ }^{97}$

A growing body of research suggests that changing the health care system to address these factors may improve the reach and effectiveness of care and create a more person-centered system. ${ }^{14,28,78,98,99}$ Several organizations and professionals play a critical role in promoting changes in the health care delivery system to improve health information, communication, informed decisionmaking, and access to clinical and public health services:

- Health care professionals

- Educators and licensing and credentialing organizations

- Accreditation organizations

- Health care executives

- Health information and library professionals

Educators and licensing, credentialing, and accreditation organizations play a unique and critical role in shaping the training and practice standards for all types of health care and public health professionals. They can lead the way in changing the skills and competencies of professionals and the organizations in which they practice and provide services. Health care executives, who often are not mentioned in discussions of health literacy improvement, can provide leadership and create and oversee the policies, goals, and performance assessments that are needed to make health literacy improvement a part of organizational culture.

\section{Strategies for Health Care Professionals (Including Anyone Who Is Part of a Health Care or Public Health Services Team)}

- Use different types of communication and tools with patients, including vetted pictures and models and scorecards, to support written and oral communication with patients and their caregivers

- Use existing programs, such as AHRQ's Questions Are the Answers, to prepare patients and providers for visits and structure their communication 
- Use direct and developmentally appropriate communication with children to build better understanding of their health and health care

- Use proven methods of checking patient understanding, such as the teach-back method, to ensure that patients understand health information and risk and benefit tradeoffs associated with treatments, procedures, tests, and medical devices

- Ensure that pharmacists provide the necessary counseling to consumers in language they understand for dispensed medications as required by law

- Use patient-centered technologies at all stages of the health care process to support the information and decisionmaking needs of patients

- Use technology, including social media, to expand patients' access to the health care team and information

- Participate in ongoing training in health literacy, plain language, and culturally and linguistically appropriate services (CLAS) and encourage colleagues and staff to be trained

- Advocate for requirements in continuing education for health care providers who have been working in the field but have not participated in health literacy, cultural competency, and language access training

- Create patient-friendly environments that facilitate communication by using architecture, images, and language to reflect the community and its values

- Refer patients to public and medical libraries to get more information and assistance with finding accurate and actionable health information

Refer patients to adult education and English language programs 


\section{Strategies in Action}

\section{Using Technology to Better Serve Those With Limited Health Literacy}

The IDEALL (Improving Diabetes Efforts Across Language and Literacy) Project at San Francisco General Hospital has found that providing patients with weekly phone calls via an automated telephone diabetes management system is effective at addressing the literacy and language needs of high-risk diabetes patients and enhancing self-management. Demonstrating improvements in communication and self-efficacy at a modest cost, especially among low-literate and LEP populations, IDEALL has proved to be an innovative approach to transforming the health care delivery system.

For more on this strategy, visit the townhall summary at http://www.health.gov/communication/literacy/TownHall/ca.htm

\section{Strategies for Educators and Licensing and Credentialing Organizations}

- Include coursework on health literacy and CLAS in curricula of all health professions

- Support health literacy and CLAS training opportunities for students and residents in all health professions

- Incorporate diverse patients, including new readers, in course presentations and trainings for health professionals

- Include assessment of health literacy and CLAS skills in licensure requirements for all health professions

- Establish minimum continuing education requirements in health literacy and CLAS for all health professions

- Increase the number of racially and ethnically diverse and/or bilingual health care professionals 


\section{Strategies in Action}

\section{Using Patient Navigators To Overcome Barriers to Care}

The Integrated Health Network (IHN) is a group of eight providers that serve more than 200,000 uninsured and underinsured residents in the city and county of St. Louis, Missouri. The Health Education and Literacy Program, a network initiative, uses lay health coaches to reach uninsured and underinsured residents and empower them to take control of their health, communicate with providers, and become more confident in navigating the health care delivery system.

Despite barriers-such as transportation access, financial obstacles, and lack of trust in the health care system - to health care among this population, results of a qualitative study determined the effectiveness of health coaches was positive. ${ }^{100}$ Preliminary findings revealed a significant increase-from 57 to 81 percent-in patients who had a primary care provider after working with a health coach. Moreover, after working with a health coach, 27 percent of chronic disease patients (up from 1 percent) were able to discuss their self-management plan.

For more on this strategy, visit the townhall summary at http://www.health.gov/communication/literacy/TownHall/mo.htm

\section{Strategies for Accreditation Organizations}

- Adopt accreditation standards for health care organizations that require care delivery systems to address health literacy and CLAS

- Incorporate health literacy and CLAS process and outcome performance measures into accreditation requirements

\section{Strategies for Health Care Executives}

- Increase awareness of and compliance with Title VI, the Americans with Disabilities Act, and other laws designed to ensure that individuals with LEP and/or disabilities have access to health information and language assistance

- Provide comprehensive language access and assistive technologies, including interpreter services, at every point of contact to meet the needs of diverse patient communities and create a person-centered environment

- Train all staff, including executives and support staff, in the principles of health literacy and CLAS 
- Remove informational barriers and create a welcoming, easy-to-navigate, shame-free environment by using such methods as well-designed signage and offering assistance with forms

- Encourage employees to take advantage of continuing education opportunities to improve communication and CLAS skills

- Integrate health literacy and CLAS audit tools, standards, and scorecards into all quality process and performance improvement activities and metrics

- Establish programs for patient navigators, health coaches (electronic and/or people), and/or community health workers to help patients access recommended services and information

- Negotiate with third-party payers on reimbursements for patient education and interpreter services

- Establish formal mechanisms to review and address the literacy level, quality of translation, and cultural appropriateness of all written information for patients

- Integrate health information technologies (e.g., electronic and personal health records) and enhance underdeveloped technology platforms to support patient-provider communication and health coaches

- Include members of patient communities, including new readers, in organizational assessments and health literacy improvement efforts

- Evaluate the contribution of poor communication and information to patient safety incidents and poor health outcomes

- Provide incentives to encourage employees to use good communication practices

- Provide patient support services, such as previsit or hospitalization reminders and postvisit and discharge followup calls, to help patients prepare and know what to do when they are home

\section{Strategies for Health Information and Library Professionals}

- Help to train all health care staff in the principles of health literacy and plain language

- Create collections or repositories of materials (e.g., insurance forms and instructions, informed consent and other legal documents, aftercare and medication instruction, and patient education materials) in several languages and review the materials with members of the target population

- Help to disseminate existing communication tools and resources for patients 


\section{Strategies in Action}

\section{Meeting the Needs of Patients With Limited Literacy Skills}

The New York City Health and Hospitals Corporation (HHC) serves 1.3 million residents, 25 percent of whom have LEP. To meet the needs of those with limited health literacy, HHC has a central repository of (1) multilingual materials that are reviewed for literacy level by multilingual staff who are trained in the principles of plain language; (2) patient-centered resources based on consumer studies; and (3) gateway resources, such as interpreters and client navigators.

For more on this strategy, visit the townhall summary at http://www.health.gov/communication/literacy/TownHall/ny.htm 


\section{Goal 3-Incorporate Accurate, Standards-Based, and Developmentally Appropriate Health and Science Information and Curricula in Child Care and Education Through the University Level}

Health literacy skills start early in life and are part of the process of caring for and educating children, adolescents, and young adults. Programs, such as Head Start, address achievement gaps in literacy beginning in the early years of a child's life. Health literacy skills are equally important, and more can be done to integrate health literacy in early child care and education. Much of early child care is informal; if not done by parents or guardians, then care is often provided by social networks of family, friends, neighbors, and private caregivers. Reaching adults, who provide the early years of care, with information about how to develop and build children's health literacy skills is essential. Recognizing the importance of the earliest years, Early Head Start programs target infants, toddlers, and their families with health and development information and programs. Research shows that children enrolled in Head Start have better access to health services and higher rates of immunization than children who are not and their parents have better coping skills and better mental health than parents of children who are not in the program. ${ }^{101}$ The Women, Infants, and Children (WIC) program that provides food, health care referrals, and health information to low-income women is another opportunity to reach people who most urgently need support to access accurate and actionable health information.

CDC and others have recognized the value of teaching functional health information in school, including the essential health skills necessary to adopt, practice, and maintain healthy behaviors. ${ }^{102}$ Health literacy is becoming more relevant as adolescents are increasingly involved with their health care ${ }^{103}$ regularly interact with the health system, and access health information that informs their actions and behaviors. ${ }^{104}$ The body of research strongly suggests that children of all ages have the potential to understand a great deal about health and how to access health information. ${ }^{105,106}$ Despite a strong evidence base and the issuance of National Health Education Standards, significant barriers to health literacy continue to exist in our Nation's schools. According to the 2004 IOM report on health literacy, the lack of consistent health curricula across grades $\mathrm{K}-12$ may reduce student health literacy. ${ }^{1}$ The National Health Education Standards can build health knowledge and skills that are critical to achieve proficient health literacy.

Several educational professionals play a critical role in integrating health literacy in early child care and education through the university level:

- Early childhood administrators, managers, and policymakers

Educational administrators, managers, and policymakers ( $\mathrm{K}-12$ and university) 
In addition to developing general literacy skills, school-based health education classes provide an excellent opportunity to facilitate the development of skills specific to health literacy, such as how to evaluate credible information on the Internet. ${ }^{107}$ Media literacy and information literacy approaches provide evidence that students can learn to be critical thinkers and seekers of health information. ${ }^{108,109}$ Numeracy skills already being developed in schools can be applied to health literacy. Schools and their libraries play a fundamental role in the development of a health literate population. Classroom-based health education, as both an independent discipline and a component of coordinated school health programs, is the nucleus for the development of health literacy in today's children and adolescents. ${ }^{110}$

\section{Strategies for Early Childhood Administrators, Managers, and Policymakers}

- Promote the availability of formal early childhood education for all eligible children

- Embed accurate, accessible, and actionable health information in all early childhood programs, such as Head Start and WIC

- Connect efforts to improve children's health literacy skills with adult programs, such as adult education courses

- Hire individuals with appropriate formal training in all child care programs

- Require coursework in health education for all students who are in postsecondary schools and preparing for a career in early childhood education

- Provide professional development for all child care teachers on the link between early childhood education literacy and health literacy

- Increase the amount of health education instruction in early childhood education

\section{Strategies for Educational Administrators, Managers, and Policymakers ( $K-12$ and University)}

- Promote health literacy by including the National Health Education Standards in school curriculum reform initiatives

- Ensure that all students can pass NAEP assessments

- Ensure that all eligible students graduate from high school

- Create and require certification standards for teachers in health education

- Require annual coursework in health literacy and health education for all students in postsecondary schools 
- Require all preservice teachers to have coursework in the instructional methods of heath education

- Build partnerships with local hospitals, clinics, health care providers, librarians, and adult education centers to connect the health literacy skill-building activities of children and adults

- Provide professional development for all teachers on health education teaching strategies, topics, skills, and age-appropriate health education

- Incorporate health education into existing science, math, literacy, social studies, and computer instruction in grades $\mathrm{K}-12$ by embedding health-related tasks, skills, and examples into lesson plans

\section{Strategies in Action}

\section{Using College Students as Agents of Change and Community Educators}

The Health Literacy Initiative of Project SHINE (Students Helping in Naturalization of Elders) engages health profession students in health literacy services for older immigrants and refugees. To address challenges with this population, Project Shine's students participated in health fairs, health education workshops, health screenings, and community needs assessments. The Health Literacy Initiative also engaged adult learners and teachers of English for speakers of other languages (ESOL) to develop a health literacy curriculum designed for older immigrant adults to use in ESOL classes, tutoring sessions, and workshops. The curriculum includes five topics: the doctor's office, the hospital, illness management, healthy aging, and medications.

For more on this strategy, visit the townhall summary at http://www.health.gov/communication/literacy/TownHall/mo.htm 


\section{Goal 4-Support and Expand Local Efforts To Provide Adult Education, English Language Instruction, and Culturally and Linguistically Appropriate Health Information Services in the Community}

Communities play a central role in supporting efforts to improve health literacy. Emphasis should be placed on community opportunities for communication, education, and peer support surrounding health information seeking and access to care. Communities and organizations can support programs, such as ESOL, at the same time that they ensure health information and services meet the linguistic needs of the populations they serve.

Several groups from the community play an important role in supporting efforts to improve health literacy:

- Educators and community service providers

- Health care team and health information and library professionals

Health care and adult education communities are natural allies in efforts to improve health literacy. These two sectors can partner to provide tools that help people navigate and access health care services. Adult education curricula have frequently-and successfully-incorporated health lessons, and adult education sectors in several States have launched health literacy initiatives. ${ }^{9}$ For example, the Virginia Adult Education Health Literacy Toolkit grew from many teachers' observations of adult literacy learners whose education paused or ended because a small health problem became bigger and brought on a host of other difficulties. ${ }^{111}$ The toolkit provides information and resources to (1) educate the educator about health care in the United States and cultural issues relating to health and (2) simplify the creation of health lessons and curricula for teachers and programs. Caregivers, whose ranks are growing, also need to be connected with adult education programs to improve their own skills and assist those for whom they care.

Libraries of all types, including public and medical libraries, have become important partners in supporting community-based health literacy efforts and working with health care professionals. Many libraries already support training programs in basic literacy. Librarians provide health information to patrons through a variety of methods-including assisting with public Internet access and searching, printing resources, referring patrons to local health services, and distributing and posting information. However, library staff members, like health professionals and health providers, require additional training so they can respond appropriately to the health literacy needs of library patrons. ${ }^{33}$ Health literacy intersects with information literacy, which is a set of abilities requiring individuals to recognize when information is needed and have the ability to locate, evaluate, and use effectively the needed information. ${ }^{109}$ 


\section{Strategies in Action}

\section{Maximizing Teachable Moments for Adult Education}

The Multicultural Resource Center, Inc., in Seffner, Florida, provides GED preparation classes and adult basic education classes for a diverse group of 18- to 83-year-old students. Mitigating the disparity between what the health care system demands and the skills of the students, staff at the Center create teachable moments to help students solve life issues and challenges. Staff help to educate the students through such activities as group discussions, certification classes, and guest speakers who talk about everyday challenges (e.g., reading prescription labels). Significant achievements include a partnership with the First Missionary Baptist Church to educate members of the community and the annual Multicultural Festival, during which information about health care and educational services is distributed.

For more on this strategy, visit the townhall summary at http://www.health.gov/communication/literacy/TownHall/fl.htm

\section{Strategies for Educators and Community Service Providers}

- Support community-based programs that empower people to be more involved and active in health and teach skills, such as computer use, to assist people in acquiring credible health information

- Infuse health literacy skills into curricula for adult literacy, ESOL, and family literacy programs

- Facilitate collaborations among the adult literacy and ESOL communities; health care partners; and community-, faith-, and academic-based organizations

- Include high school, college, and professional school students in health literacy programs to bridge cultural and generational divides

- Collaborate with medical librarians to create health information centers in public libraries

- Train more librarians and reference staff in health literacy skills and health information technologies so they can help to build the health literacy skills of patrons

- Create opportunities for health education and learning in communities through creative uses of technology and multimedia

- Provide professional development in health education topics and skills for those teaching adult literacy, ESOL, and family literacy programs 


\section{Strategies in Action}

\section{Facilitating Collaborations Between Adult Educators and Health Care Professionals}

The Adult Learning Center, the New York City Office of the Mayor, the Harvard School of Public Health, the Literacy Assistance Center, and the Harlem Hospital Center piloted a health literacy study circle-an innovative approach that infuses health literacy skills into an adult education curriculum. Through such activities as tours of health care facilities, literacy instructors and students gained context for their work on health literacy skills and a stronger comfort level with the health care system. The health care organizations gained insight into the needs of low-literate and immigrant populations. The Literacy Assistance Center reports that through partnerships between the adult educators and health professionals, many adult literacy students were able to acquire health insurance and become more knowledgeable of specific health issues and health services in their communities, and health professionals have become more culturally and linguistically attuned to the needs of patients. Partnering has also contributed to building community capacity, as each agency shares resources and works to address the same disadvantaged population. ${ }^{112}$

For more on this strategy, visit the townhall summary at http://www.health.gov/communication/literacy/TownHall/ny.htm

\section{Strategies for the Health Care Team and Health Information and Library Professionals}

- Become familiar with information and literacy resources in your community and refer consumers to them

- Invite adult education classes to visit your health center and adult education students to speak at meetings and symposia

- Be a guest lecturer in an adult education class, serve as a curriculum advisor, or otherwise collaborate with adult educators in your community

- Build ongoing partnerships with community organizations and local libraries to support the health information needs in the community 


\section{Strategies in Action}

\section{Partnerships Between Local Libraries and Hospitals}

The Santa Clara (California) Medical Center, Santa Clara County Library, and Plane Tree Health Library have partnered since 2001 to operate a center for health literacy on the campus of the medical Center. The community learning center provides information about a variety of medical topics and conditions in English, Spanish, and Vietnamese in a variety of formats (print, audio, and video) with a focus on easy-to read materials. The Medical Center provides readily accessible space to patients; the Plane Tree Library provides supervision and expertise in resource development; and the Santa Clara Library recruits adult literacy students to visit the Center and provide literacy support to patrons referred by health care providers.

For more on this strategy, visit the townhall summary at http://www.health.gov/communication/literacy/TownHall/ca.htm 


\section{Goal 5-Build Partnerships, Develop Guidance, and Change Policies}

Productive partnerships among all types of organizations and professional groups will go a long way toward identifying and implementing the most effective strategies and actions to improve health literacy. Organizations and professions can go it alone, but progress toward the goals will be faster and more sustainable with consensus on common strategies, outcomes, interventions, and products among many organizations, associations, and agencies:

- Philanthropic, nonprofit, voluntary, advocacy, academic, and professional organizations

- Government agencies

The organizational base should expand beyond traditional health care and educational sectors and include philanthropic, nonprofit, voluntary, advocacy, academic, and professional associations. These organizations often provide funding for research and interventions, develop and disseminate health information, advocate for priorities and programs, and even deliver health services in communities. They can convene stakeholder groups and provide input to public sector plans and projects. Private institutions can build commitment among national health associations and other stakeholders to promote health literacy. They are well-positioned to coordinate action on literacy and health by establishing links between national health associations and the Federal government, literacy organizations, and State and local health service providers. ${ }^{1}$

Nonprofit, voluntary, advocacy, and professional associations can inform and educate consumers about their rights and responsibilities and help them to use health care services more effectively. They can help to educate health care providers about the need to communicate health information clearly. They can give providers tools to improve their communication skills. They may also publish evidence-based decision aids and guides for diverse audiences. Through publications, Web sites, and events, such organizations contact millions of consumers and health professionals each year. They provide information and services that can model health literacy practices.

Public health agencies must also play a more prominent role because of their population-based approach and their responsibility to promote and protect the health of all. Such agencies have a wide range of activities that directly connect to health literacy. For example, they develop and disseminate health information, pay for and deliver health care services, collect data on population health issues, and conduct evaluations of interventions to determine effectiveness. Public health agencies also develop regulations, policies, guidelines, and forms that affect the practices of other organizations, such as schools and employers. Developing and sustaining productive partnerships that integrate health literacy with traditional public health and connect public health with the other sectors identified in this plan are essential to achieving goals. One example is the national network of community-based aging 
organizations in every community in the country. They consist of State offices on aging, tribal organizations, area agencies on aging, family caregivers, service providers and volunteers to provide home- and community-based services to older individuals.

\section{Strategies in Action}

\section{Building a Statewide Health Literacy Campaign}

Health Literacy Missouri (HLM), an initiative of the Missouri Foundation for Health, works to strengthen health literacy and improve health communication across Missouri. In the 2 years since its start, HLM has begun a health literacy awareness campaign and is creating a Statewide health literacy surveillance system. Initial efforts include developing a model to map health literacy in Missouri and identifying communities with people who have limited health literacy skills, compiling an inventory of health literacy resources for health professionals, and promoting training and understanding of health literacy among journalists.

For more on this strategy, visit the townhall summary at http://www.health.gov/communication/literacy/TownHall/mo.htm

\section{Strategies for Philanthropic, Nonprofit, Voluntary, Advocacy, Academic, and} Professional Organizations

- Include health literacy in strategic plans, requests for proposals, grant awards, programs, and educational initiatives

- Develop funding guidelines for health literacy projects that can be shared across sectors

- Identify areas for guidelines and standards development to foster clear communication and usable health information and services

Work with communities to develop cost-effective strategies for health literacy improvement

- Participate in and help to recruit cross-disciplinary coalitions to promote and advocate for health literacy improvement

- Increase and leverage funding for health literacy initiatives - both alone and integrated into existing programs

Facilitate the sharing of resources and tools for improving health literacy

- Educate policymakers and other decisionmakers about the need to communicate health issues clearly and about the importance of health literacy and its contributions to improvements in health outcomes and decreased costs 


\section{Strategies in Action}

\section{Integrating Adult Learners in the Provision of Health Care}

The lowa Health System partners with New Readers of lowa to make health care more understandable to adult learners and others. Much of their work involves making small changes that have a big impact on improving access to and understanding of the health care system. New Readers review health forms, serve on committees, and participate in needs assessments to offer the adult learner's point of view about health literacy. As Archie Willard, the founder of New Readers of lowa said, "To me, the words health literacy are a call to action for medical doctors, medical professionals, and adults who have reading problems to work together to improve communications to receive better health care. The adult learner needs to be at the table and their voices should be heard. No one can tell our stories for us."

For more on this strategy, visit the townhall summary at http://www.health.gov/communication/literacy/TownHall/mo.htm

\section{Strategies for Government Agencies}

- Review, analyze, and propose changes to existing laws, policies, and regulations that make it difficult to use all types of health information (e.g., general health and safety, medication, health care coverage and financing, and informed consent)

- Assess the need for an Office of Health Literacy to provide a focal point for health literacy improvement activities

- Support national and State data collection on health literacy factors

- Use census and survey data to map limited health literacy "hot spots" and prioritize interventions and resources for communities and individuals with the most limited health literacy

- Collaborate across government bureaucracies - such as public health, education, transportation, social services, and environmental and occupational health and global health-to provide clear and consistent public information about health issues and recommendations

- Facilitate public discussion about health information and services needed in communities to support better health outcomes

- Support research and evaluation studies that examine health literacy factors in the study of other issues, such as patient safety, emergency preparedness, and health care costs 
- Identify areas for guidelines and standards development to foster clear communication and usable health information and services and apply existing guidelines and standards in plain language and CLAS

- Use clear communication in all public communication and approve the use of clear communication by nongovernmental organizations that have their public information reviewed by government agencies 


\section{Goal 6-Increase Basic Research and the Development, Implementation, and Evaluation of Practices and Interventions To Improve Health Literacy}

Many of the health literacy intervention studies to date have been relatively small in size. Much of the evidence on interventions comes from improving doctor-patient communication, simplifying written materials, and using video or other supplementary materials. More studies are needed that compare more than one intervention. ${ }^{113}$ Various health professionals are critical to such studies:

- Researchers, evaluators, and funders

- Public health professionals

Government agencies, foundations, and research universities should prioritize funding for qualitative and quantitative studies related to health literacy improvement.

\section{Strategies for Researchers, Evaluators, and Funders}

- Identify and address gaps, such as numeracy and visual communication, in health literacy research

- Collaborate to develop a national research agenda and include health literacy innovations and interventions in research plans and goals

- Develop more rigorous and comprehensive methods to measure individual and population health literacy skills that capture the full range of skills, including listening and speaking, writing, numeracy, and cultural and conceptual knowledge

Develop methods to measure or estimate health literacy skills at local levels

- Develop methods to measure the full range of health literacy skills of health professionals and organizations

- Conduct studies of the economic impact of limited health literacy

- Explore technology-based interventions to improve health literacy

- Assess barriers and strategies to improve access to health information and navigation of the health care system

- Support systematic reviews and evaluations of effectiveness and implementation of health literacy interventions 
- Evaluate existing health literacy interventions for their impact on (1) people's ability to use health information and services more effectively and (2) cost, safety, and health outcomes

- Include health literacy interventions in other research areas, such as chronic diseases, patient safety, immunizations, and health equity (i.e., an individual's ability to attain his or her full health potential regardless of social position or other socially determined circumstances)

- Develop and implement health literacy interventions based on theories and models-drawing from such related disciplines as communication, education, cognitive science, and medical sociology

- Expand interventions beyond the clinic and into community settings and engage in communitybased participatory research

- Remove barriers that prevent persons with limited health literacy skills from participating in clinical trials and other health-related studies

Include health literacy measures in national and other surveys

\section{Strategies for Public Health Professionals}

- Explore the feasibility and utility of a health literacy scorecard or composite index for individual and system monitoring of health literacy on a national or sub-national level

- Include health literacy measures in public health data collection and surveillance

- Increase support for systems- and community-based research in health literacy improvement

- Include health literacy factors in the evaluation of public health interventions in such other areas as chronic disease prevention and management 


\section{Goal 7-Increase the Dissemination and Use of Evidence-Based Health Literacy Practices and Interventions}

Advances in health care are limited by a failure to translate research findings into practice. ${ }^{114}$ Original research may take as long as one or two decades to be put into routine clinical practice. ${ }^{115}$ Increasing health literacy research is not enough-especially if the research is not used to create evidence-based interventions or the interventions are not widely disseminated to organizations, professionals, and consumers. The disciplines of communication and social marketing could make significant contributions to shaping research and practice on dissemination activities.

The literature suggests that passive diffusion (e.g., clinical practice guidelines; mass mailing; and presentations to large, heterogeneous groups) is largely ineffective in achieving widespread program adoption. ${ }^{116,117}$ Ineffective dissemination wastes scarce resources. Effective dissemination of evidencebased programs often requires a more active, systematic, and controlled approach and strong organizational commitment. ${ }^{118,119,120,121}$

Several groups play critical roles in disseminating and using evidence-based health literacy practices and interventions:

- Researchers, academic organizations and journals, and health information and library professionals

Professional associations, advocacy groups, and funders

But dissemination is not an end in itself. Intended benefits depend on integration and implementation by end users who will also determine the relevance and usability of whatever is disseminated. ${ }^{122}$ Therefore, end users need to be considered early in the process of generating the research they might use. Interactive engagement and dialogue with the public is also vital to disseminating and using evidencebased health literacy research.

\section{Strategies for Researchers, Academic Organizations and Journals, and Health Information and Library Professionals}

- Actively engage practitioners, community members, consumers, and policymakers in the research process

- Use participatory approaches to help shape research questions and ensure greater relevance, credibility, and implementation

- Use a variety of channels and formats to disseminate evidence-based research findings that are appropriate to the target audiences, including health professionals and adult educators 
- Consider developing a health literacy Web site

- Emphasize dissemination as an essential step in the scientific process and a fundamental part of public health principles

- Explore new mechanisms to pull together and share data and research findings as they become available

- Speed dissemination of results of health literacy research to practitioners, communities, policymakers, and researchers in other disciplines

- Report on findings, such as conditions when evidence-based practices did not work in specific situations or populations

- Collaborate to develop and disseminate trade and consumer pieces to accompany scientific articles

\section{Strategies for Professional Associations, Advocacy Groups, and Funders}

- Increase funding for dissemination and implementation research of evidence-based health literacy interventions

- Increase resources for technical assistance, training, and time for researchers, grantees, and health care providers to build the capacity to disseminate and implement evidence-based interventions

- Provide access to evidence-based information and tools about interventions

- Develop guidance on how to change practice as a result of research findings

- Support networks of researchers and practitioners to facilitate learning and changes in practices

- Encourage members and researchers to report on gaps in evidence-based practices and interventions that did not work in practice

- Require strategic dissemination plans that go beyond publishing in academic journals 


\section{Strategies in Action}

\section{Identifying Service Gaps and Developing an Inventory of Resources}

When a needs assessment revealed a gap in professionals' access to health literacy tools and resources, the St. Louis University School of Public Health and Missouri Health Literacy Enhancement (MHLE) compiled an inventory of health literacy resources for health professionals. The database currently holds more than 10,000 resources-including tools, educational materials, scientific literature, surveys, and curricula. The easy-to-use system walks users through a series of steps that are designed to assist them in identifying resources. Each item in the database includes a description, user reviews, recommended resources, and evaluation and scoring information. The database is still in the development phases, and the school hopes to obtain feedback on the prototype in the coming months.

For more on this strategy, visit the townhall summary at http://www.health.gov/communication/literacy/TownHall/mo.htm 


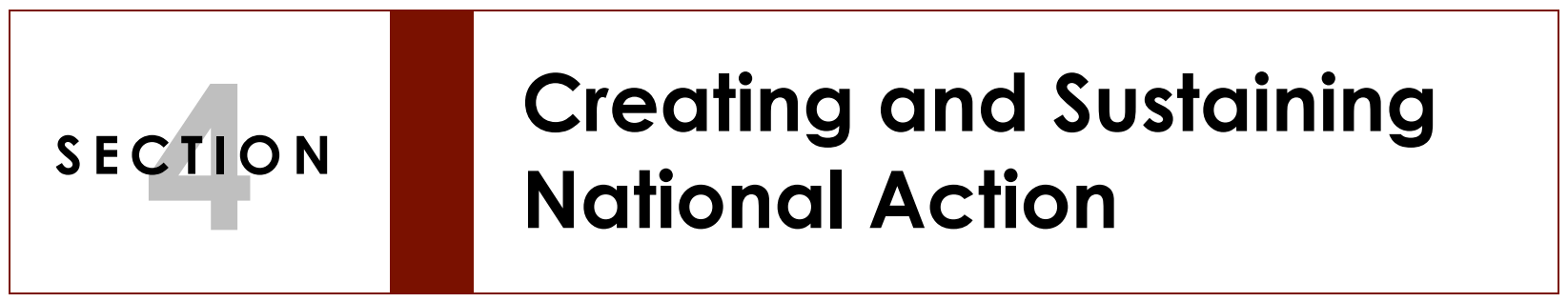

$\mathrm{T}$ ranslating these strategies and opportunities into meaningful action will require great commitment on the part of a broad range of individuals, communities, professions, and organizations. Each of us has a role to play in advancing the principle that all Americans have the right to accurate and actionable health information. A successful societal response to limited health literacy requires coordination, communication, and evaluation. The following six principles should be used to create and sustain national action to improve health literacy:

1. Actions should be cross-disciplinary. Partnerships among all levels of government, public and private institutions, health care providers, educators, and community groups will increase the likelihood that gaps will be addressed.

2. Actions should be strategically planned and based on evidence. The choice of action should be based on feasibility, effectiveness, and suitability. Organizations and institutions should develop a strategic process to achieve improvements in health literacy.

3. Actions should be evaluated. Groups should document the short- and long-term effects of efforts to improve health literacy whenever possible. Furthermore, information, findings, successes, and lessons learned should be shared widely.

4. Actions should involve continued public education on the extent and associations of limited health literacy.

5. Actions should include laws, policies, and similar institutional supports that facilitate health literacy.

6. Actions should involve communities and individuals that are most affected by limited health literacy.

This National Action Plan to Improve Health Literacy aims to stimulate a societywide movement to make the vision of a health literate America a reality. No single action will be sufficient, and disconnected actions will not create the scale of change required. This plan provides an integrated framework to bring together organizations and people at all levels of society to work for fundamental changes in the design and delivery of health information and services. 
Access to accurate and actionable health information and usable health services is a matter of fundamental fairness and empowerment. Without such access, we cannot hope to realize the promises of medical research, health information technology, and advances in health care delivery. The Nation must come together to change the way we communicate about health. 


\section{APPENDIX References}

1. Nielsen-Bohlman, L., Panzer, A. M., \& Kindig, D. A. (Eds.). (2004). Health literacy: A prescription to end confusion. Washington, DC: National Academies Press.

2. Kutner, M., Greenberg, E., Jin, Y., \& Paulsen, C. (2006). The health literacy of America's adults: Results from the 2003 National Assessment of Adult Literacy (NCES 2006-483). Washington, DC: U.S. Department of Education, National Center for Education Statistics.

3. Rudd, R. E., Anderson, J. E., Oppenheimer, S., \& Nath, C. (2007). Health literacy: An update of public health and medical literature. In J. P. Comings, B. Garner, \& C. Smith. (Eds.), Review of adult learning and literacy (vol. 7) (pp 175-204). Mahwah, NJ: Lawrence Erlbaum Associates.

4. U.S. Department of Health and Human Services. (2000). Healthy People 2010 (2nd ed.) [with Understanding and Improving Health (vol. 1) and Objectives for Improving Health (vol. 2)]. Washington, DC: U.S. Government Printing Office.

5. Berkman, N. D., DeWalt, D. A., Pignone, M. P., Sheridan, S. L., Lohr, K. N., Lux, L., et al. (2004). Literacy and health outcomes (AHRQ Publication No. 04-E007-2). Rockville, MD: Agency for Healthcare Research and Quality.

6. Office of Disease Prevention and Health Promotion. (2006). Expanding the reach and impact of consumer e-health tools. Washington, DC: U.S. Department of Health and Human Services.

7. Adams, K., \& Corrigan, J. M. (Eds.). (2003). Priority areas for national action: Transforming health care quality. Washington, DC: National Academies Press.

8. Institute of Medicine. (2009). Toward health equity and patient-centeredness: Integrating health literacy, disparities reduction, and quality improvement: Workshop summary. Washington, DC: National Academies Press.

9. Office of Disease Prevention and Health Promotion. (2003). Communicating health: Priorities and strategies for progress. Washington, DC: U.S. Department of Health and Human Services.

10. Schwartz, L. M., Woloshin, S., Black, W. C., \& Welch, H. G. (1997). The role of numeracy in understanding the benefit of screening mammography. Annals of Internal Medicine, 127(11), 966972.

11. National Institute for Health Literacy. (2008). What is health literacy? Retrieved June 2, 2009, from http://www.nifl.gov/nifl/faqs.html

12. Rudd, R., Moeykens, B. A., \& Colton, T. C. (2000). Health and literacy: A review of the medical and public health literature. In J. Comings, B. Gerners, \& C. Smith (Eds.), Annual review of adult learning and literacy. New York: Jossey-Bass. 
13. United Nations Economic and Social Council. (2009). Draft ministerial declaration of the 2009 highlevel segment of the Economic and Social Council: Implementing the internationally agreed goals and commitments in regards to global public health. Geneva, Switzerland: Author.

14. Parker, R. M., Wolf, M. S., \& Kirsch, I. (2008). Preparing for an epidemic of limited health literacy: Weathering the perfect storm. Journal of General Internal Medicine, 23(8), 1273-1276.

15. U.S. Department of Health and Human Services. (2008). Healthy People 2010: Objective 11-2 data. Retrieved August 20, 2008, from http://wonder.cdc.gov/data2010/focus.htm

16. Helitzer, D., Hoolis, C., Cotner, J., \& Oestreicher, N. (2009). Health literacy demands of written health information materials: An assessment of cervical cancer prevention materials. Cancer Control, 16(1), 70-78.

17. Goodfellow, G. W., Trachimowicz, R., \& Steele, G. (2008). Patient literacy levels within an inner-city optometry clinic. Optometry, 79(2), 98-103.

18. Badarudeen, S., \& Sabharwal, S. (2008). Readability of patient education materials from the American Academy of Orthopaedic Surgeons and Pediatric Orthopaedic Society of North America Web sites. The Journal of Bone and Joint Surgery American Volume, 90(1), 199-204.

19. Hill-Briggs, F., \& Smith, A. S. (2008). Evaluation of diabetes and cardiovascular disease print patient education materials for use with low-health literate populations. Diabetes Care, 31(4), 667-671.

20. Schwartzberg, J. G., Cowett, A., VanGeest, J., \& Wolf, M. S. (2007). Communication techniques for patients with low health literacy: A survey of physicians, nurses, and pharmacists. American Journal of Health Behavior, 31(S1), S96-S104.

21. Coben, D., Colwell, D., Macrae, S., Boaler, J., Brown, M., \& Rhodes, V. (2003). Adult numeracy: Review of research and related literature. London: National Research and Development Centre for Adult Literacy and Numeracy.

22. Golfin, P., Jordan, W., Hull, D., \& Ruffin, M. (2005). Strengthening mathematics skills at the postsecondary level: Literature review and analysis. Washington, DC: U.S. Department of Education, Office of Vocational and Adult Education.

23. Kirsch, I. S., Jungeblut, A., Jenkins, L., \& Kolstad, A. (1993). Adult literacy in America: A first look at the findings of the National Adult Literacy Survey (NCES 93275). Washington, DC: U.S. Department of Education.

24. Grabois, E. W., \& Nosek, M. A. (2001). The Americans With Disabilities Act and medical providers: Ten years after passage of the act. Policy Studies Journal, 29(4), 682-689.

25. Grabois, E. W., Nosek, M. A., \& Rossi, C. D. (1999). Accessibility of primary care physicians' offices for people with disabilities: An analysis of compliance with the Americans With Disabilities Act. Archives of Family Medicine, 8(1), 44-51.

26. Alliance for Excellent Education. (2007). The high cost of high school dropouts: What the nation pays for inadequate high schools (Issue Brief). Washington, DC: Author. Retrieved June 18, 2009, from http://www.all4ed.org/publications/HighCost.pdf

27. Olson, L. (2007). Improving children's chances. Education Week, 26(17), 10-14. 
28. Davis, T. C., Wolf, M. S., Bass, P. F. III, Middlebrooks, M., Kennen, E., Baker, D. W., et al. (2006). Low literacy impairs comprehension of prescription drug warning labels. Journal of General Internal Medicine, 21(8), 847-851.

29. Davis, T. C., Wolf, M. S., Bass, P. F. III, Thompson, J. A., Tilson, H. H., Neuberger, M., et al. (2006). Literacy and misunderstanding prescription drug labels. Annals of Internal Medicine, 145(12), 887894.

30. Rothman, R. L., Housam, R., Weiss, H., Davis, D., Gregory, R., Gebretsadik, T., et al. (2006). Patient understanding of food labels: The role of literacy and numeracy. American Journal of Preventive Medicine, 31(5), 391-398.

31. Wolf, M. S., Davis, T. S., Tilson, H. H., Bass, P. F., \& Parker, R. M. (2006). Misunderstanding of prescription drug warning labels among patients with low literacy. American Journal of HealthSystem Pharmacy, 63, 1048-1055.

32. Baker, D. W., Wolf, M. S., Feinglass, J., \& Thompson, J. A. (2008). Health literacy, cognitive abilities, and mortality among elderly persons. Journal of General Internal Medicine, 23(6), 723-726.

33. Juzych, M. S., Randhawa, S., Shukairy, A., Kaushal, P., Gupta, A., \& Shalauta, N. (2008). Functional health literacy in patients with glaucoma in urban settings. Archives of Ophthalmology, 126(5), 718-724.

34. Parikh, N. S., Parker, R. M., Nurss, J. R., Baker, D. W., \& Williams, M. V. (1996). Shame and health literacy: The unspoken connection. Patient Education and Counseling, 27(1), 33-39.

35. Wolf, M. S., Williams, M. V., Parker, R. M., Parikh, N. S., Nowlan, A. W., \& Baker, D. W. (2007). Patients' shame and attitudes toward discussing the results of literacy screening. Journal of Health Communication, 12(8), 721-732.

36. Baker, D. W., Parker, R. M., Williams, M. V., Ptikin, K., Parikh, N. S., Coates, W., et al. (1996). The health care experience of patients with low literacy. Archives of Family Medicine, 5(6), 329-334.

37. Barrett, S. E., Puryear, J. S., \& Westpheling, K. (2008). Health literacy practices in primary care settings: Examples from the field. New York: The Commonwealth Fund.

38. Rogers, E. S., Wallace, L. S., \& Weiss, B. D. (2006). Misperceptions of medical understanding in lowliteracy patients: implications for cancer prevention. Cancer Control. 13(3), 225-229.

39. Parker, R. (2000). Health literacy: A challenge for American patients and their health care providers. Health Promotion International, 15(4), 277-283.

40. Howard, D. H., Gazmararian, J., \& Parker, R. M. (2005). The impact of low health literacy on the medical costs of Medicare managed care enrollees. American Journal of Medicine, 118, 371-377.

41. Vernon, J. A., Trujillo, A., Rosenbaum, S., \& DeBuono, B. (2007). Low health literacy: Implications for national policy. Retrieved November 30, 2008, from http://www.gwumc.edu/sphhs/ departments/healthpolicy/chsrp/downloads/LowHealthLiteracyReport10 4 07.pdf

42. Kelly, P. A., \& Haidet, P. (2007). Physician overestimation of patient literacy: A potential source of health care disparities. Patient Education and Counseling, 66(1), 119-122. 
43. Osborn, C. Y., Paasche-Orlow, M. K., Davis, T. C., \& Wolf, M. S. (2007). Health literacy: An overlooked factor in understanding HIV health disparities. American Journal of Preventive Medicine, 33(5), 374-378.

44. Sentell, T. L., \& Halpin, H. A. (2006). Importance of adult literacy in understanding health disparities. Journal of General Internal Medicine, 21(8), 862-866.

45. Parker, R. M. (2009, February 26). Vision: Where do we want to go in terms of measuring health literacy? Presentation at the Institute of Medicine Health Literacy Roundtable Workshop on Measures of Health Literacy, Washington, DC.

46. World Health Communication Associates. (2009). Health literacy: Part 1-The basics. United Kingdom: Author.

47. Blanson Henkemans, O. A., Rogers, W. A., Fisk, A. D., Neerincx, M. A., Lindenberg, J., \& van der Mast, C. A. (2008). Usability of an adaptive computer assistant that improves self-care and health literacy of older adults. Methods of Information in Medicine, 47, 82-88.

48. Townsend, M. S., Sylva, K., Martin, A., Metz, D., \& Wooten-Swanson, P. (2008). Improving readability of an evaluation tool for low-income clients using visual information processing theories. Journal of Nutrition Education Behavior, 40(3), 181-186.

49. Robinson, L. D. Jr., Calmes, D. P., \& Bazargan, M. (2008). The impact of literacy enhancement on asthma-related outcomes among underserved children. Journal of the National Medical Association, 100(8), 892-896.

50. Yin, H. S., Dreyer, B. P., van Schaick, L., Foltin, G. L., Dinglas, C., \& Mendelsohn, A. L. (2008). Randomized controlled trial of a pictogram-based intervention to reduce liquid medication dosing errors and improve adherence among caregivers of young children. Archives of Pediatric Adolescent Medicine, 162(9), 814-822.

51. Cooper, L. A., Beach, M. C., \& Clever, S. L. (2005). Participatory decision-making in the medical encounter and its relationship to patient literacy. In J. G. Schwartzberg, J. B. VanGeest, \& C. C. Wang (Eds.), Understanding health literacy: Implications for medicine and public health (pp. 141-154). Chicago: AMA Press.

52. Davis, T. C., Holcombe, R. F., Berkel, H. J., Pramanik, S., \& Divers, S. G. (1998). Informed consent for clinical trials: A comparative study of standard versus simplified forms. Journal of the National Cancer Institute, 90(9), 668-674.

53. Gustafson, D. H., Hawkins, R., Boberg, E., Pingree, S., Serlin, R. E., Graziano, F., et al. (1999). Impact of a patient-centered, computer-based health information/support system. American Journal of Preventive Medicine, 16(1), 1-9.

54. Jibala-Weiss, M. L., Volk, R. J., Friedman, L. C., Granchi, T. S., Neff, N. E., Spann, S. J., et al. (2006). Preliminary testing of a just-in-time, user-defined values clarification exercise to aid lower literate women in making informed breast cancer treatment decisions. Health Expectations, 9(3), 218.

55. Neuhauser, L., \& Kreps, G. L. (2003). Rethinking communication in the e-health era. Journal of Health Psychology, 8(1), 7-23. 
56. Neuhauser, L. (2001). Participatory design for better interactive health communication: A statewide model in the U.S.A. Electronic Journal of Communication/La Revue Electronique de Communication, 11 (3 and 4).

57. Nielsen, J. (2000). Designing Web usability. Indianapolis: New Riders Publishing.

58. Taub, H. A., Baker, M. T., \& Sturr, J. F. (1986). Effects of readability, patient age, and education. Journal of the American Geriatrics Society, 34, 601-606.

59. Vaiana, M. E., \& McGlynn, E. A. (2002). What cognitive science tells us about the design of reports for consumers. Medical Care Research and Review, 59(1), 3-35.

60. Zarcadoolas, C., Pleasant, A., \& Greer, D. S. (2006). Advancing health literacy: A framework for understanding and action. San Francisco: Jossey-Bass.

61. Kripalani, S., Robertson, R., Love-Ghaffari, M. H., Henderson, L. E., Praska. J., Strawder, A., et al. (2007). Development of an illustrated medication schedule as a low-literacy patient education tool. Patient Education and Counseling, 66(3), 368-377.

62. Katz, M. G., Kripalani, S., \&Weiss, B. D. (2006). Use of pictorial aids in medication instructions: A review of the literature. American Journal of Health-System Pharmacy, 63(23), 2391-2397.

63. Ancker, J. S., Senathirajah, Y., Kukafka, R., \& Starren, J. B. (2006). Design features of graphs in health risk communication: A systematic review. Journal of the American Medical Informatics Association, 13(6), 608-618.

64. Lipkus, I. M., Samsa, G., \& Rimer, B. K. (2001). General performance on a numeracy scale among highly educated samples. Medical Decision Making, 21(1), 37-44.

65. Paasche-Orlow, M. K., Schillinger, D., Greene, S. M., \& Wagner, E. H. (2006). How health care systems can begin to address the challenge of limited literacy. Journal of General Internal Medicine, $21,884-887$.

66. Bass, P. F., Wilson, J. F., Griffith, C. H., \& Barnett, D. R. (2002). Residents' ability to identify patients with poor literacy skills. Academic Medicine, 77(10), 1039-1041.

67. Parker, R., \& Kreps, G. L. (2005). Library outreach: Overcoming health literacy challenges. Journal of the Medical Library Association, 93(4), S81-S85.

68. Gerber, B. S., Brodsky, I. G., Lawless, K. A., Smolin, L. I., Arozullah, A. M., Smith, E. V., et al. (2005). Implementation and evaluation of a low-literacy diabetes education computer multimedia application. Diabetes Care, 28(7), 1574-1580.

69. Sudore, R. L., Landefeld, C. S., Barnes, D. E., Lindquist, K., Williams, B. A., Brody, R., et al. (2007). An advance directive redesigned to meet the literacy level of most adults: A randomized trial. Patient Education and Counseling, 69(1-3), 165-195.

70. Hawkins, R. H., Kreuter, M., Resnicow, K., Fishbein, M., \& Dijkstra, A. (2008). Understanding tailoring in communicating about health. Health Education Research, 23(3), 454-466.

71. DeWalt, D. A., Malone, R. M., Bryant, M. E., Kosnar, M. C., Corr, K. E., Rothman, R. L., et al. (2006). $A$ heart failure self-management program for patients of all literacy levels: A randomized, controlled trial. BMC Health Services Research, 6, 30. 
72. Rudd, R. (2006). Functional health literacy: Health information in everyday life. In Proceedings from the Surgeon General's Workshop on Improving Health Literacy (pp. 11-13). Retrieved November 30, 2008, from http://www.surgeongeneral.gov/topics/healthliteracy/pdf/ proceedings120607.pdf

73. Jacobson, K. L., Gazmararian, J. A., Kripalani, S., McMorris, K. J., Blake, S. C., \& Brach, C. (2007). Is our pharmacy meeting patients' needs? A pharmacy health literacy assessment tool user's guide (AHRQ Publication No. 07-0051). Rockville, MD: Agency for Healthcare Research and Quality. Retrieved October 14, 2009, from http://www.ahrq.gov/qual/pharmlit/index.html

74. Sudore, R. L., Landefeld, C. S., Williams, B. A., Barnes, D. E., Lindquist, K., \& Schillinger, D. (2006). Use of a modified informed consent process among vulnerable patients: A descriptive study. Journal of General Internal Medicine, 21(8), 867-873.

75. Primack, B. A., Bui, T., \& Fertman, C. I. (2007). Social marketing meets health literacy: Innovative improvement of health care providers' comfort with patient interaction. Patient Education and Counseling, 68(1), 3-9.

76. Schlichting, J. A., Quinn, M. T., Heuer, L. J, Schaefer, C. T, Drum, M. L, \& Chin, M. H. (2007, December). Provider perceptions of limited health literacy in community health centers. Patient Education and Counseling, 69(1-3), 114-120.

77. Brashares, D. E., Boldsmith, D. J., \& Hsieh, E. (2002). Information seeking and avoiding in health contexts. Human Communication Research, 28, 258-271.

78. Zorn, M., Allen, M., \& Horowitz, A. (2004). Understanding health literacy and its barriers (Current Bibliographies in Medicine 1). Bethesda, MD: National Library of Medicine.

79. Pribble, J. M., Goldstein, K. M., Fowler, E. F., Greenberg, M. J., Noel, S. K., \& Howell, J. D. (2006). Medical news for the public to use? What's on local TV news. American Journal of Managed Care, 12(3), 170-176.

80. Schwitzer, G., Mudur, G., Henry, D., Wilson, A., Goozner, M., Simbra, M., et al. (2005). What are the roles and responsibilities of the media in disseminating health information? PLoS Medicine, 2(7), e215.

81. Smith, E. (2008, August 22). Health journalists face translation challenge, Missouri journalism researchers find. Missouri University News.

82. Sudore, R. L., Landefeld, C. S., Pérez-Stable, E. J., Bibbins-Domingo, K., Williams, B. A., \& Schillinger, D. (2009). Unraveling the relationship between literacy, language proficiency, and patientphysician communication. Patient Education and Counseling, 75, 398-402.

83. American College of Physicians Foundation. (2007). Improving prescription drug container labeling in the United States: A health literacy and medication safety initiative. Retrieved August 20, 2009, from http://foundation.acponline.org/medlabel.htm

84. Institute of Medicine. (2008). Standardizing medication labels: Confusing patients less-Workshop summary. Washington, DC: National Academies Press. 
85. National Council on Patient Information and Education. (2007). Enhancing prescription medicine adherence: A national action plan. Bethesda, MD: Author. Retrieved October, 14, 2009, from http://www.talkaboutrx.org/documents/enhancing prescription medicine adherence.pdf

86. Shrank, W., Avorn, J., Rolon, C., \& Shekelle, P. (2007). Effect of content and format of prescription drug labels on readability, understanding, and medication use: A systematic review. The Annals of Pharmacotherapy, 41(5), 783-801.

87. National Association of Boards of Pharmacy. (2009, February). Report of the Task Force on Uniform Prescription Labeling Requirements. Mount Prospect, IL: Author.

88. U.S. Pharmacopeia. (2009). 2008 Health literacy and prescription container labeling advisory panel: Meeting 2. Rockville, MD: U.S. Pharmacopeia.

89. Office of Disease Prevention and Health Promotion. (2008). Town hall meeting on improving health literacy in Sacramento, California: Meeting summary. Retrieved October 15, 2009, from http://www.health.gov/communication/literacy/TownHall/ca.htm

90. Office of Disease Prevention and Health Promotion. (2008). Town hall meeting on improving health literacy in Tampa Bay, Florida: Meeting summary. Retrieved October 15, 2009, from http://www.health.gov/communication/literacy/TownHall/fl.htm

91. Kreps, G. (2006). Communication and racial inequities in health care. American Behavioral Scientist, 49, 760-774.

92. Williams, M., Davis, T., Parker, R., \& Weiss, B. (2002). The role of health literacy in patient-physician communication. Family Medicine, 34, 383-389.

93. Barrett, S. E., Dyer, C., \& Westpheling, K. (2008). Language access: Understanding the barriers and challenges in primary care settings. Perspectives from the field. McLean, VA: Association of Clinicians for the Underserved.

94. Yedidia, M. J., Gillespie, C. C., Kachur, E., Schwartz, M. D., Ockene, J., Chepaitis, A. E., et al. (2003). Effect of communications training on medical student performance. Journal of the American Medical Association, 290(9), 1157-1165.

95. Shin, H. B., \& Bruno, R. (2003). English use and language English-speaking ability: 2000. Retrieved November 30, 2008, from http://www.census.gov/prod/2003pubs/c2kbr-29.pdf

96. Flores, G. (2006). Lost in translation: Language barriers, literacy, communication, and quality in health care. In Proceedings from the Surgeon General's Workshop on Improving Health Literacy (pp. 23-25). Retrieved November 30, 2008, from http://www.surgeongeneral.gov/topics/ healthliteracy/pdf/proceedings120607.pdf

97. U.S. Department of Health and Human Services. (2005). Surgeon General's call to action to improve the health and wellness of persons with disabilities. Retrieved December 14, 2009, from http://www.surgeongeneral.gov/library/disabilities/calltoaction/calltoaction.pdf

98. Schillinger, D. (2006). Literacy, chronic disease care, and public healthcare systems: A focus on communication. In Proceedings from the Surgeon General's Workshop on Improving Health Literacy (pp. 13-16). Retrieved November 30, 2008, from http://www.surgeongeneral.gov/ topics/healthliteracy/pdf/proceedings120607.pdf 
99. Parker, R., Ratzan, S. C., \& Lurie, N. (2003). Health literacy: A policy challenge for advancing highquality health care. Health Affairs, 22(4), 147-153.

100. Office of Disease Prevention and Health Promotion. (2008). Town hall meeting on improving health literacy in St. Louis, Missouri: Meeting summary. Retrieved October 15, 2009, from http://www.health.gov/communication/literacy/TownHall/mo.htm

101. National Head Start Association. (n.d.). Head Start works! (Issue Brief). Alexandria, VA. Retrieved August 20, 2009, from http://www.nhsa.org/research/head start facts

102. Centers for Disease Control and Prevention. (2007). Health Education Curriculum Analysis Tool. Atlanta: U.S. Department of Health and Human Services.

103. Gray, N. J., Klein, J. D., Noyce, P. R., Sesselberg, T. S., \& Cantrill, J. A. (2005). Health informationseeking behaviour in adolescence: The place of the Internet. Social Science \& Medicine, 60(7), 1467-1478.

104. Manganello, J. A. (2009). Health literacy and adolescents: An agenda for the future. Retrieved June 12, 2009, from http://www.neahin.org/healthliteracy/Images/Manganello\%20Paper.pdf

105. Keil, F. (2006). Meeting the health literacy needs of young children. In Proceedings from the Surgeon General's Workshop on Improving Health Literacy (pp. 28-29). Retrieved November 30, 2008, from http://www.surgeongeneral.gov/topics/healthliteracy/pdf/proceedings120607.pdf

106. Brown, S. L., Teufel, J. A., \& Birch, D. A. (2007). Early adolescents perceptions of health and health literacy. Journal of School Health, 77(1), 7-15.

107. Davis, T. C., Wolf, M. S., Arnold, C. L., Byrd, R. S., Long, S. W., Springer, T., et al. (2006). Development and validation of the Rapid Estimate of Adolescent Literacy in Medicine (REALMTeen): A tool to screen adolescents for below-grade reading in health care settings. Pediatrics, 118(6), 1707-1714.

108. Hobbs, R., \& Frost, R. (2003). Measuring the acquisition of media literacy skills. Reading Research Quarterly, 38(3), 330-355. Retrieved on July 23, 2009, from http://www.reading.org/Publish.aspx?page=/publications/journals/rrq/v38/i3/abstracts/ $\underline{\text { rrq-38-3-hobbs.html\&mode=redirect }}$

109. American Library Association. (2000). Information literacy competency standards for higher education. Retrieved July 23, 2009, from http://www.ala.org/ala/mgrps/divs/acrl/ standards/standards.pdf

110. Deal, T. B., \& Hodges, B. (2009). Role of 21st century schools in promoting health literacy. Retrieved June 12, 2009, from http://www.neahin.org/healthliteracy/Images/BenhamDeal-Hodges\%20Paper.pdf

111. Singleton, K. (2003). Virginia Adult Education Health Literacy Toolkit. Retrieved June 16, 2009, from http://www.aelweb.vcu.edu/publications/healthlit/sections/toolkit.pdf

112. Office of Disease Prevention and Health Promotion. (2007). Town hall meeting on improving health literacy at Baruch College, New York: Meeting summary. Retrieved October 15, 2009, from http://www.health.gov/communication/literacy/TownHall/ny.htm

113. Hoffman, A., \& Pearson, S. K. (2009). Marginal medicine: Targeting comparative effectiveness research to reduce waste. Health Affairs, 28(4), w710-w718. 
114. Feldstein, A. C., \& Glasgow, R. E. (2008). A Practical, Robust Implementation and Sustainability Model (PRISM) for integrating research findings into practice. The Joint Commission Journal on Quality and Patient Safety, 34(4), 228-243

115. Agency for Healthcare Research and Quality. (2001). Translating research into practice (TRIP)-II: Fact sheet. Retrieved June 16, 2009, from http://www.ahrq.gov/research/trip2fac.htm

116. Kerner, J., Rimer, B., \& Emmons, K. (2005). Introduction to the special section on dissemination: Dissemination research and research dissemination: How can we close the gap? Health Psychology, 24, 443-446.

117. Bero, L. A., Grilli, R., Grimshaw, J. M., Harvey, E., Oxman, A. D., \& Thomson, M. A. (1998). Closing the gap between research and practice: An overview of systematic reviews of interventions to promote the implementation of research findings. BMJ, 317(7156), 465-468.

118. Lomas, J. (1993). Diffusion, dissemination, and implementation: Who should do what? Annals of the New York Academy of Sciences, 703, 226-235.

119. Sallis, J. F., Owen, N., \& Fotheringham, M. J. (2000). Behavioral epidemiology: A systematic framework to classify phases of research on health promotion and disease prevention. Annals of Behavioral Medicine, 22(4), 294-298.

120. Rabin, B. A., Brownson, R. C., Kerner, J. F., \& Glasgow, R. E. (2006). Methodologic challenges in disseminating evidence-based interventions to promote physical activity. American Journal of Preventive Medicine, 31(4S), S24-S34.

121. Ellis, P., Robinson, P., Ciliska, D., Sussman, J., Raina, P., Armour, T., et al. (2005). A systematic review of studies evaluating diffusion and dissemination of selected cancer control interventions. Health Psychology, 24(5), 488-500.

122. Green, L. W., Ottoson, J. M., García, C., \& Hiatt, R. A. (2009). Diffusion of theory and knowledge dissemination, utilization, and integration in public health. Annual Review of Public Health, 30, 151-174. 
Y ou have an important part to play in improving health literacy. You can talk to your friends, family, librarians, and coworkers about health literacy and get involved in the community. You can become an advocate for your own health with your providers, employers, and policymakers.

Here is a list of steps that you can take to start improving health literacy where you live.

\section{For Individuals and Families}

\section{Improve Communication With Your Doctors and Other Health Professionals}

- Write down or record information from your doctors and their staff.

- Ask your doctor, nurse, and pharmacist and other people in the office, clinic, pharmacy, or hospital to use familiar language.

- Ask questions if something is not clear. Know who to call if you have questions when you get home.

- Let your doctor and others who care for you know if you can't understand what they are telling you about your health. If the information is confusing or complicated, ask for materials written in plain language.

- Volunteer to go with a friend or loved one to their next medical appointment (if culturally appropriate). Help them take notes and ask questions. (Note: Family members should not be expected to act as medical interpreters.)

- Take advantage of existing communication tools and resources for patients, including standardized questions to ask your doctor. 


\section{Work With Your Library and Other Community Organizations}

- Inform local public health and safety officials about the community's need for clear health communication. Take advantage of existing feedback channels (e.g., public Web sites, community forums, librarians, or suggestion boxes) to request public health information that is written in plain language.

- Share information, stories, and trusted sources of health information with friends and family. If you need help to find reliable sources, ask your local public or medical librarian.

- Use libraries and librarians to locate good quality, relevant health information. Take classes offered by librarians on Internet and social media tools.

Talk to local elected officials about the importance of health literacy in your communities.

- Attend health education programs at your local public or hospital library, community centers, or faith-based organizations. Request these programs, if they aren't offered.

- Request information and services that are clear and easy to use to support prevention and healthy living.

\section{Help Improve Health Education at Home and in Schools}

- Start with improving general education:

- Read to your children every day and improve your own literacy skills.

- Encourage teens to graduate from high school, and support them if they need help.

- Participate in activities that involve the whole family in Kindergarten to Grade 12 curriculum to reinforce what is learned in the classroom.

- Advocate for quality education for all students in the community to help ensure that all students graduate with the skills they need to be healthy adults.

- If you need to improve your literacy and English language skills, enroll in GED, English for speakers of other languages and other skill-building courses. If classes are full, advocate for more resources for these classes in your community.

Next, work on improving health education:

- Request that local school curricula include health education.

- Ask for clear and actionable health messages, such as hand-washing, in school communications. 
- Advocate for national assessments of health knowledge in Grades 4, 8, and 12.

- Volunteer with local adult education, English language instruction, or similar community learning organizations that help people find and use health information.

\section{For Communities}

- Start a health column in the local newspaper or create a health program on local radio or cable access television. Invite local doctors, public health officials, educators, and community members to participate.

- Work with sponsors of local health care events (e.g., health fairs, public workshops, or free screenings) to spread the word about improving health literacy.

- Organize health education programs and sponsor presentations and meetings at your local public or hospital library, community centers, or faith-based organizations.

- Work with your local public health officer and city officials to ensure that important public health and safety information is communicated in plain language.

- Review the health education curriculum used in local schools. If there is no health education component, advocate for its inclusion.

- Encourage your public libraries to include current and reliable health information resources as part of their collections.

- Provide classes to build health literacy skills.

- Form a health literacy coalition.

- Organize a town hall meeting around issues of health literacy.

- Use local and community media to raise community awareness about the effects of limited health literacy and community needs for better health information and services.

\section{For Educators}

- Organize a trip to a local hospital, clinic, library, or adult education center.

- Invite health care professionals and health educators and communicators to make presentations to your students. 
- Involve parents in health education homework.

- Share health literacy information and resources with your colleagues.

- Start a health literacy club so that students become involved.

- Find ways to integrate health literacy skills into other subject areas. 


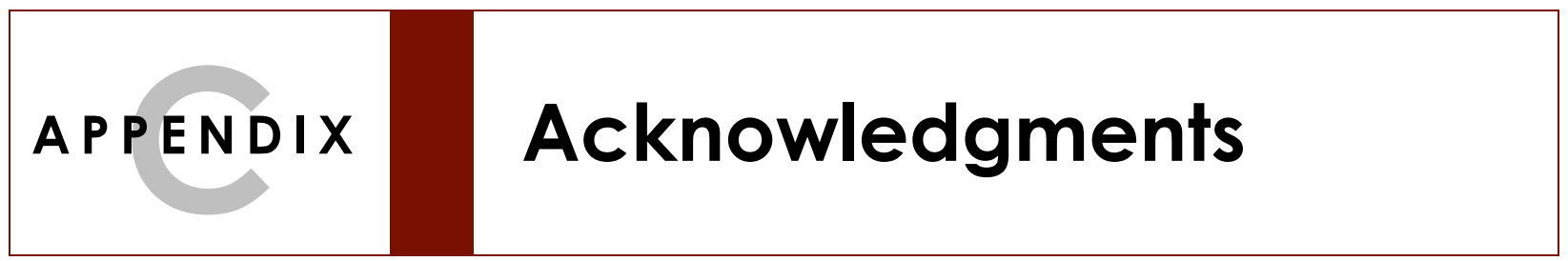

Lead Editor

Cynthia Baur, Ph.D.

Senior Advisor, Health Literacy

Office of the Associate Director for Communication

Centers for Disease Control and Prevention

Contributing Editors

\section{Centers for Disease Control \& Prevention}

- Carolyn Brooks, M.A.

- Sulma (Jessica) Herrera, M.P.H.

\section{Office of Disease Prevention and Health Promotion}

- Sean Arayasirikul, M.S.P.H., C.H.E.S.

- Linda Harris, Ph.D.

- Joanne Locke, M.A.S.

- Charlotte Neuhaus, M.H.S.

- Stacy Robison, M.P.H., C.H.E.S.

- Sandra Williams Hilfiker, M.A.

U.S. Department of Health and Human Services, Health Literacy Workgroup

Administration on Aging

- Agency for Healthcare Research and Quality

- Assistant Secretary for Planning and Evaluation

- Centers for Disease Control and Prevention 
- Centers for Medicare \& Medicaid Services

- Health Resources and Services Administration

- Indian Health Service

- National Institutes of Health

- Office of Disease Prevention and Health Promotion

- Office of Minority Health

- Office on Women's Health

- Substance Abuse and Mental Health Services Administration

- U.S. Food and Drug Administration

\section{Stakeholder Organizations That Participated in Meetings on the Plan}

- Academy of General Dentistry

- Aetna

- Alliance of the American Dental Association

- American Academy of Pediatrics

- American Association of Colleges of Nursing

- American Association of Health Educators

- American Association of Public Health Dentistry

- American Association of Retired Persons

- American College of Healthcare Executives

- American College of Physicians Foundation

- American Dental Association

- American Dental Association Foundation

- American Dental Hygienists Association

- American Dietetic Association

- American Medical Association

- American Public Health Association

- American Society of Health-System Pharmacists

- American Speech Language \& Hearing Association

- America's Health Insurance Plans

- Association for Supervision and Curriculum Development 
- Association of Clinicians for the Underserved

- Blue Cross and Blue Shield Association

- Center for Plain Language

- Consumer Healthcare Products Association

- Emergency Nurses Association-Park Ridge

- Hispanic Dental Association

- Institute of Medicine

- Johnson \& Johnson

- Joint Commission

- Kaiser Commission on Medicaid and the Uninsured

- Medical Library Association

- Medicare Rights Center

- Merck

- Missouri Foundation for Health

- National Alliance for Hispanic Health

- National Association of Boards of Pharmacy

- National Association of Medical Communicators

- National Association of State Boards of Education

- National Board of Medical Examiners

- National Coalition for Literacy

- National Dental Association

- National Institute for Literacy

- National School Boards Association

- Office of the Surgeon General

- Partnership for Clear Health Communication at the National Patient Safety Foundation

- Public Library Association

- Red Cross

- Society for Public Health Education

- United Healthcare

- University of Maryland

- Walter Reed Army Medical Center 
New York Town Hall Partners

- New York City Mayor's Office

- Literacy Assistance Center

- 144 participants from the public

\section{California Town Hall Partners}

- California Department of Managed Health Care

- Health Research for Action, University of California, Berkeley, School of Public Health

- 101 participants from the public

\section{Missouri Town Hall Partners}

- Missouri Foundation for Health

- 146 participants from the public

\section{Florida Town Hall Partners}

- Tampa Bay Community Cancer Network

- 84 participants from the public

\section{Presenters at Surgeon General's Workshop on Improving Health Literacy}

- David W. Baker, M.D., M.P.H.

- Glenn D. Flores, M.D., F.A.A.P.

- Vicki S. Freimuth, Ph.D.

- Judith Hibbard, Dr.P.H.

- Frank C. Keil, Ph.D.

- RADM Kenneth P. Moritsugu, M.D., M.P.H.

- Linda Neuhauser, Dr.P.H.

- Denise Park, Ph.D.

- Michael P. Pignone, M.D., M.P.H. 
- RADM Penelope Slade Royall, P.T., M.S.W.

- Rima E. Rudd, M.S.P.H., Sc.D.

- Dean Schillinger, M.D.

- William A. Smith, Ed.D.

- Grover J. (Russ) Whitehurst, Ph.D.

- Christina Zarcadoolas, Ph.D. 


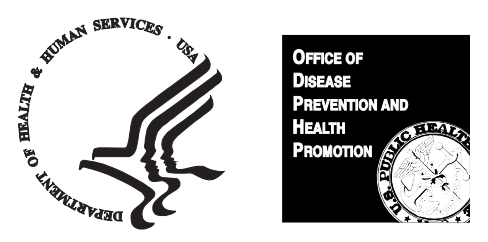

\section{U.S. Department of Health and Human Services}

Office of Disease Prevention and Health Promotion

May 2010 